\title{
The Barriers and Facilitators of Covid-19 Patient Care: A Conventional Content Analysis
}

\author{
Elham Navab ${ }^{1}$, Nasibeh Barani ${ }^{2}$, Parvaneh Asgari $^{3}$, Fatemeh Bahramnezhad $^{4}$
}

\begin{abstract}
Background \& Aims: Epidemics and their consequences have widespread effects on health care workers. Since hospital work environments are under high workload, complexity, and chaos, and are constantly changing due to different medical and care developments. During epidemic and pandemic crises, this situation is exacerbated by an increase in the number of patients and lack of resources, resulting in an increased likelihood of physical and mental vulnerability of staff. In this regard, the Covid-19 pandemic has caused physical and psychological challenges for hospital staff more than the previous epidemic, especially since the high prevalence and mortality rate of the virus is the most important challenge in this field. The other common unprecedented consequence of these conditions can be depression, anxiety, insomnia, and burnout of staff especially among the elderly and experienced staff. These secondary consequences have negative impacts on the quality of the services provided by the staff and act as major barriers to effective health care delivery. However, despite the many barriers, some facilitators can facilitate and improve the delivery of different services. For example, protective actions, social distancing, and widespread detective strategies, and detection of patients can play an important role in controlling the disease and thus reducing the workload of health staff. Therefore, identifying barriers and facilitators in health care delivery for patients can be helpful in the management of this pandemic and we can rely on them to provide the basis for further studies and thus better planning. Therefore, this study aimed to explore the barriers and facilitators of caring for Covid-19 patients.

Materials \& Methods: This qualitative study was conducted in 2020 employing Conventional content analysis Approach. In this study, semi-structured interviews were conducted with 11 physicians and 14 nurses who were working in the Covid-19 units of hospitals affiliated to Tehran University of Medical Sciences and were willing to participate in the study. In order to follow the social distancing, all interviews were conducted virtually via Skype, WhatsApp, and by phone at intervals of 45 to 60 minutes by an experienced interviewer. Some interviews were conducted visually and some orally at the request of the interviewee. Interviews were continued until the data saturation and not reaching the new code in the last three interviews. Data analysis was performed according to the proposed steps of Granheim and Landman. Finally, the interviews were transcribed, typed, and read several times to extract the original codes. The codes were then merged and classified based on the similarities, and finally the hidden concepts were extracted from the data.

Results: A total of five themes and 14 subthemes were extracted from 340 initial codes in this study. The themes of this study were double-edged sword culture, individual factors, changes in care approach, organizational factors, and ethical challenges. In the theme of double-edged sword culture, two sub-themes of 'collectivistic culture' and 'facilitator culture' emerged. The cultural diversity of the community has created problems for the management of this disease and even the care of patients. Ignoring social distancing despite the warnings of Ministry of Health officials due to adherence to customs such as visiting and handshaking, had led to the spread of the disease and made its control difficult. Especially in the dominant Iranian culture, shaking hands is a custom and wearing gloves and masks is not a routine. On the other hand, in the culture of collectivism, they also help and cooperate with others, as they produced protective equipment and disinfectants through teamwork. Others encouraged inpatients by providing virtual communication through virtual networks which helped the treatment

1. Department of Critical Care Nursing, School of Nursing and Midwifery, Tehran University of Medical Sciences, Tehran, Iran

2. Department of Critical Care Nursing, School of Nursing and Midwifery, Tehran University of Medical Sciences, Tehran, Iran

${ }^{3}$. Department of Critical Care Nursing, School of Nursing and Midwifery, Tehran University of Medical Sciences, Tehran, Iran

${ }^{4}$. Nursing and Midwifery Care Research Center, School of Nursing and Midwifery, Spiritual Health Group, Research Center of Quran, Hadith and Medicine, Tehran University of Medical Sciences, Tehran, Iran (Corresponding author) Tel: 00982161054416 Email: bahramnezhad@sina.tums.ac.ir
\end{abstract}


team and facilitated the caring process. Due to the rapid spread of the disease, the treatment team, in addition to being afraid of being a carrier, also had emotional problems due to quarantine. But having the idea that the nurses should not put stress on others, enduring psychological and physical stress as a result of the situation became more difficult. In this regard, in the theme of individual factors, three sub-themes of 'fear', 'emotional emptiness', and 'ambassador of peace' emerged. The nature of the disease, the use of protective equipment by the personnel, social distancing, changes in patient communication, changes in professional interactions, and feelings of powerlessness in virus management have all been challenges for the treatment team in caring for these patients. This condition has also affected nurse-nurse or physician-nurse interactions. But the pandemic made another change in the treatment team, and that was teamwork. Medical and nursing staff stated that they had not cooperated closely before for various reasons and refused to work as a team, but lack of equipment, insufficient knowledge about the disease had instinctively brought the treatment team closer to each other and all tried to do their best to eliminate the disease. Thus, 'care metamorphosis', 'communication', 'missing links in care and treatment', and 'integration' were the three sub-themes emerging in the theme of change in the approach to care. The themes of organizational factors included lack of necessary infrastructure, lack of equipment, manpower and lack of adequate space for patient care, but they were encouraged and continued to work with the support of hospital managers, the Deputy Minister of Health and the support of the Minister of Health. The four sub-themes of 'structural problems', 'lack of manpower', 'insufficient equipment', and 'lack of organizational support' were the most important obstacles for the treatment team in providing the best therapeutic performance. Another theme that emerged in this study was moral distress with two sub-themes of 'guilt' and 'moral helplessness' in which the individual raised issues such as lack of privacy, and not being at the bedside of a dying patient as his main concerns. Lack of privacy, reliance on writing the last name on the clothes and not introducing themselves to the patient at the beginning of the patient admission due to high workload and lack of time, elimination of the principle of respect for autonomy, lack of regular patient visits in the final stages of life except moral distress are discussed and classified.

Conclusion: According to the results, culture, individual, and organizational factors can be considered as both barriers and facilitators. But ethical challenges, as an important obstacle, can cause burnout in the medical staff. It is suggested that the authorities provide more psychological support to the treatment team, or give them a recovery period by employing new staff and reducing the workload of the treatment team. Also, getting help from a psychologist and psychiatrist, encouraging people to exercise, meditation and music can help strengthen the workforce in hospitals. Therefore, authorities should plan to increase the resilience of the medical staff in emerging and man- made phenomena such as the Covid-19 pandemic.

Keywords: Barriers, Facilitators, Covid-19, Nurse, Physician, Care, Qualitative Research

\section{Conflict of Interest: No}

How to Cite: Navab E, Barani N, Mohaddess F, Asgari P, Bahramnezhad F. The Barriers and Facilitators of Covid-19 Patient Care: A Conventional Content Analysis. Iran Journal of Nursing. 2021; 34(131):82-97.

Received: 17 May 2021

Accepted: 21 Aug 2021 


\title{
تبين موانع و تسهيل كرهاى ارائه مراقبت به بيماران كوويد- 19: تحليل محتواى عرفى
}

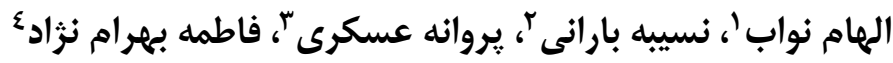

جكيله

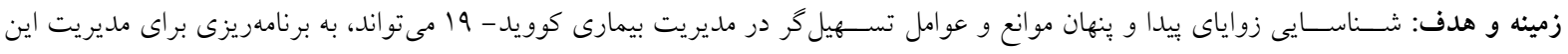

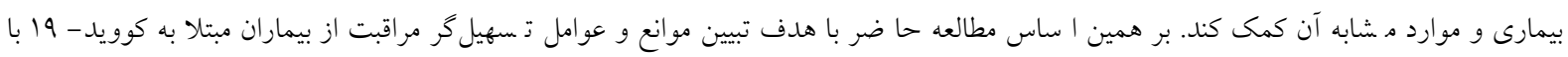
رويكرد تحليل محتواى عرفى انجام شد.

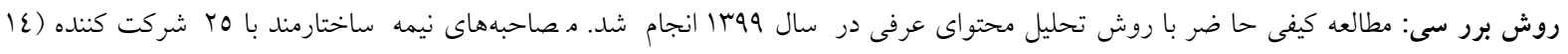

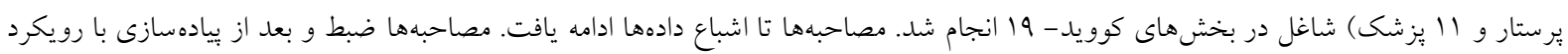
كرانهايم و لاندمن تحليل شدند.

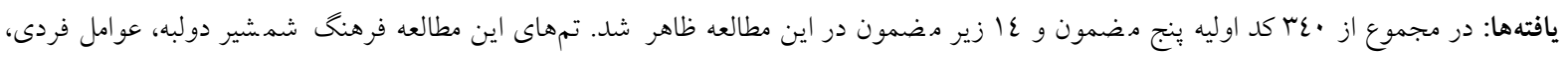

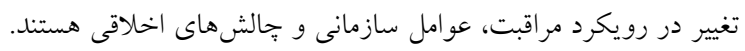

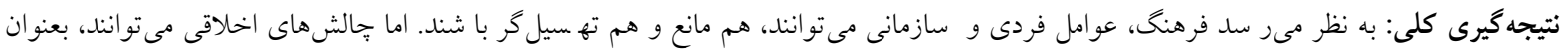

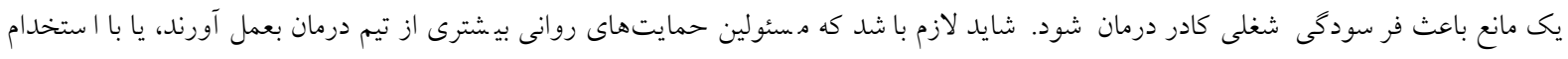

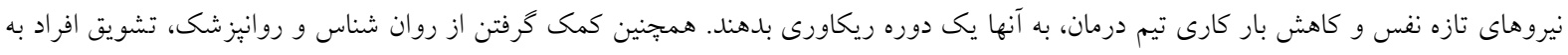

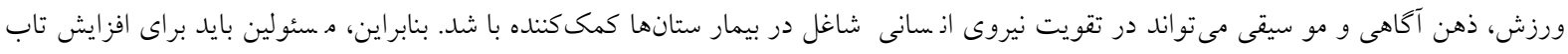

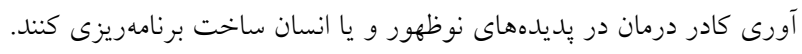

كليد وازهها: موانع، تسهيل گر، كوويد- 19، برستار، بزشك، مراقبت، تحقيق كيفى

تعارض منافع: ندارد

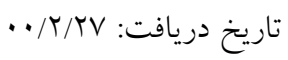

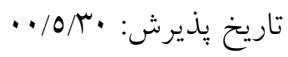

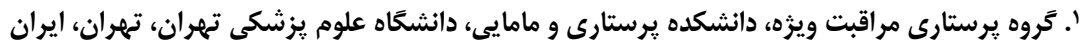

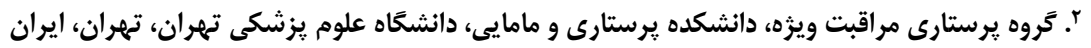

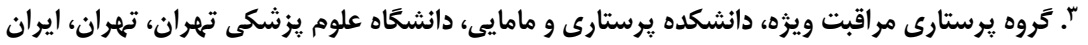

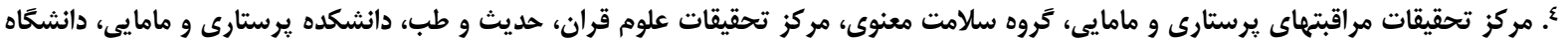
E-mail: bahramnezhad@sina.tums.ac.ir 
و وحشــت"، اصــلى ترين بديدة تجر به شــــه در بين

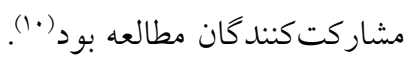

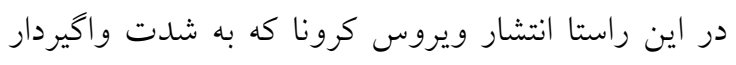

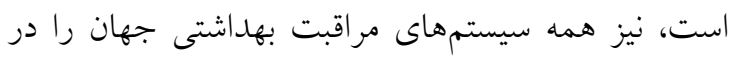

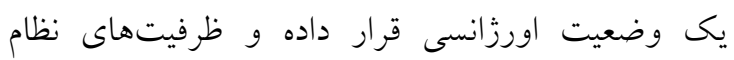

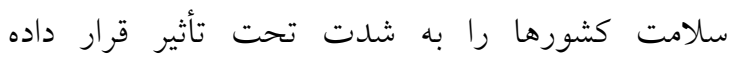

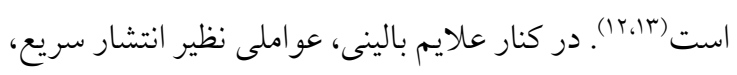

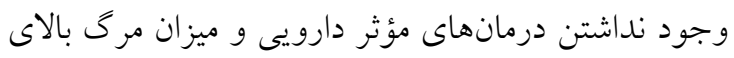
اين بيمارى، به شدت طبقات مختلف اجتماعى با جايخاه

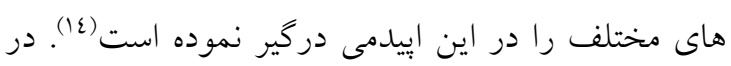

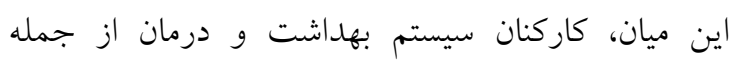
يز شكان و برستاران در خط اول مبارزه با اين بيمارى قرار

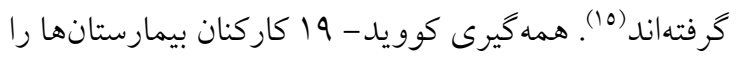

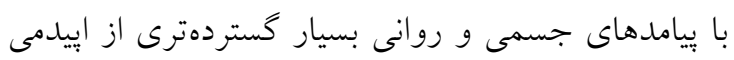

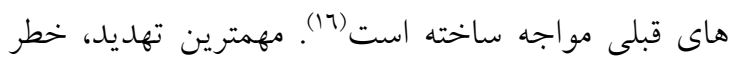

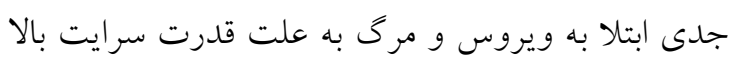

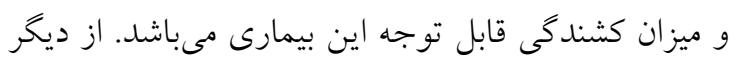

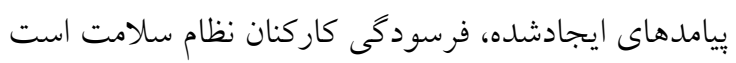

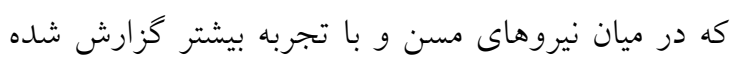

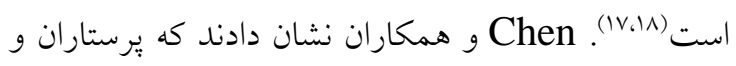

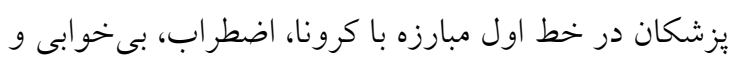

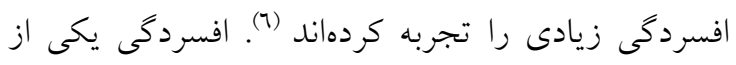

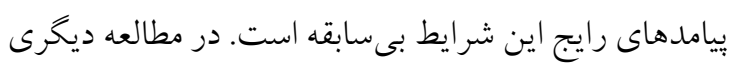

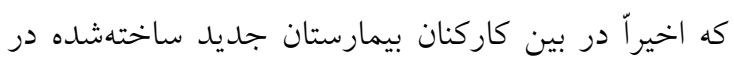
Wuhan

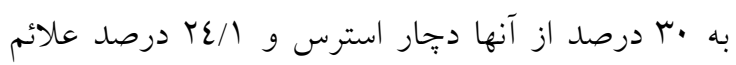

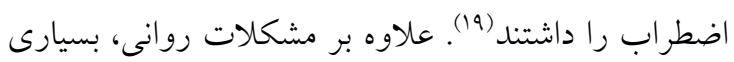
از كاركنان بهلاشتى دجار مشكلات جسمى و اختلال در

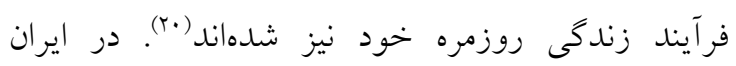

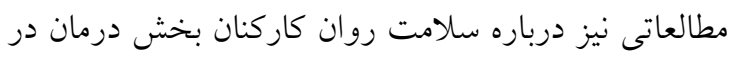

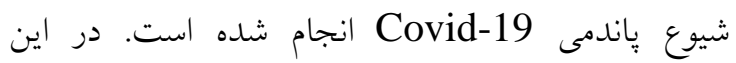

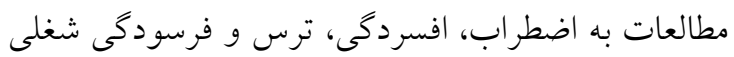

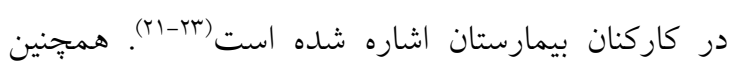

مقلمهه إيبدمى ها و ابعاد بيرامون آن اثرات كســردهاى بر كاركنان

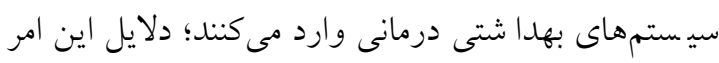

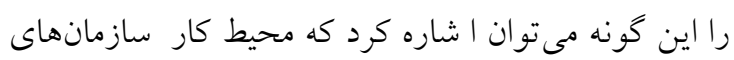

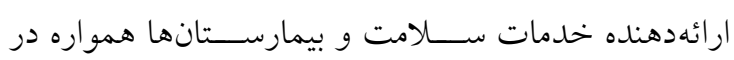

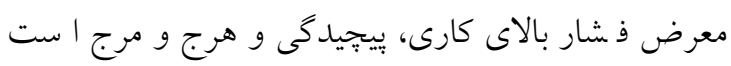

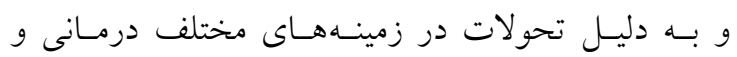

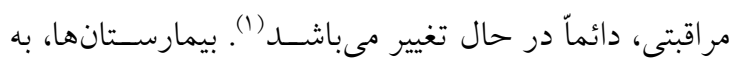
طور ذاتى محيطهاى ير استرس بوده و كاركنان آن به طور

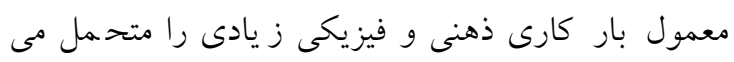

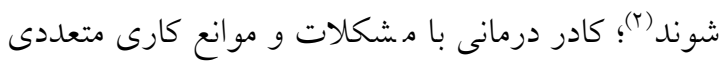

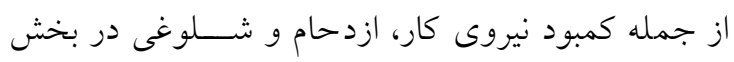

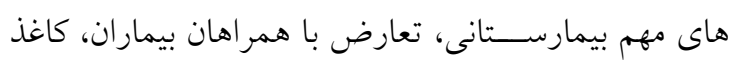

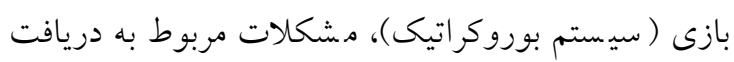

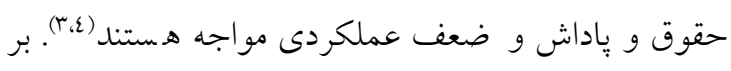

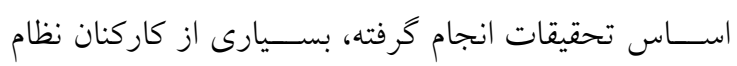

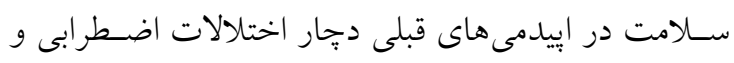
عاطفى شـــــه بودند. براى مثال، تعدادى از محققين اعلام

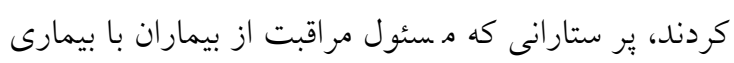

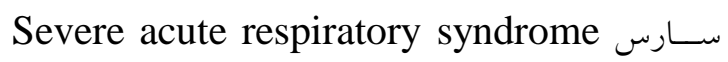
بودند، سطوح بالاترى از اختلالات ا ضطراب،

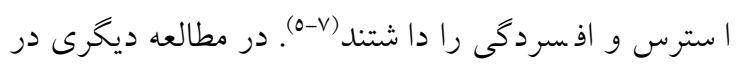

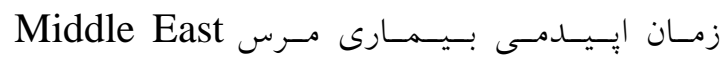
Respiratory Syndrome (MERS)

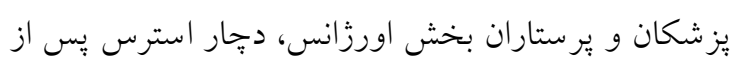
حادثه (Past trauma stress disorder (PTSD) شده بودند (^). از ديخر مشكلات اين افراد در دوران إيدمى (Pادى

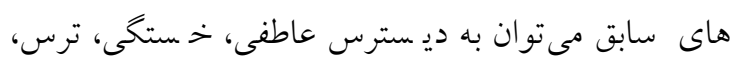
وحشت و استرس هاى روانى به علت دورى از خانواده و

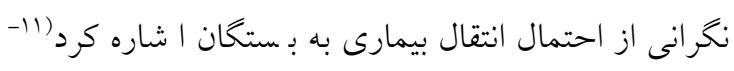

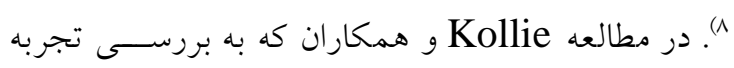

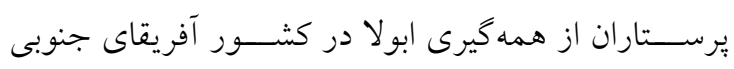

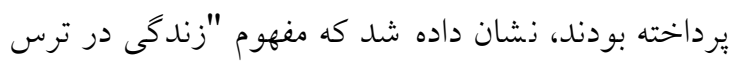


اســفاده مداوم از تجهيزات حفاظت فردى تأثير زيادى بر

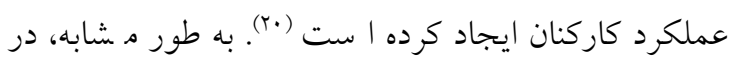

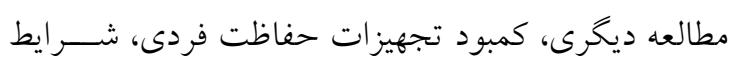

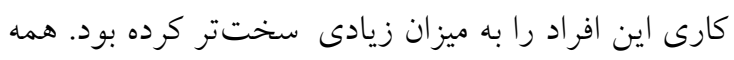

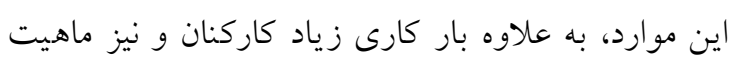

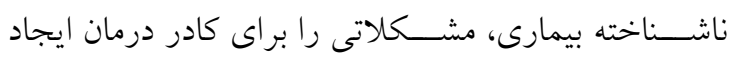
كرده است (r.) در اين ميان و بر خلاف موانع موجود در مدقا بل ارائه

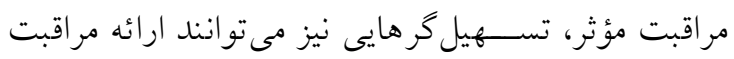

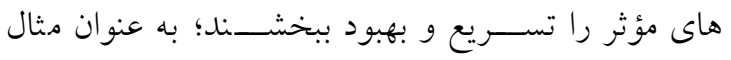

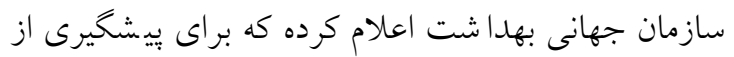
همه كَيرى اين ويروس، رعايت اقدامات حفاظتى و فاصله

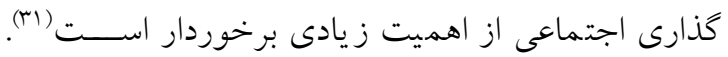

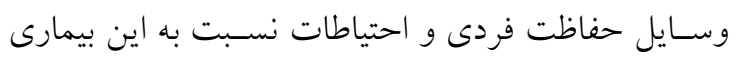
شامل استفاده از ماسك N95، كان، دستكش، كلاه، عينى و جّمه و بسترى بيمار در اتاق ايزوله با فشار منفى اعلام

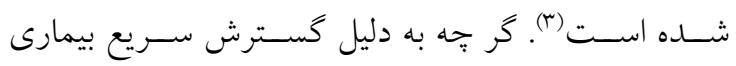

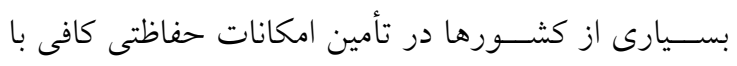

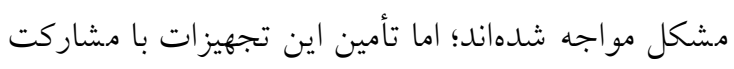

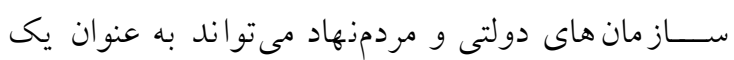

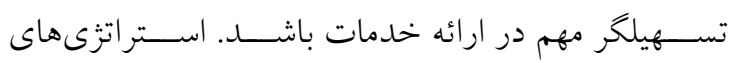
ك سترده تشخي صى و شنا سايى بيماران نيز به عنوان اين

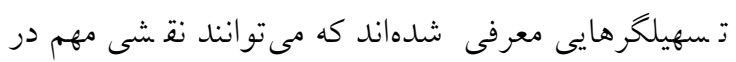

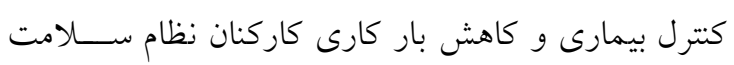
شود (rr) خطر شيوع يكى پاندمى و همد كيرى جهانى ممكن است،

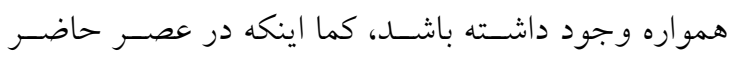
شيوع ويروس كروناى جديد در كنار مرى و مير و تبعات

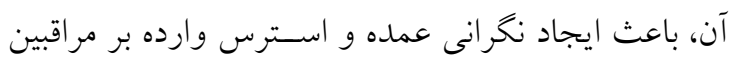

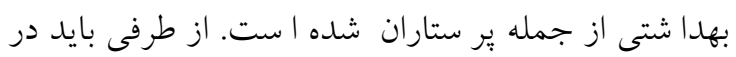

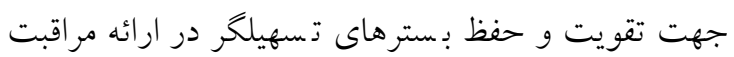

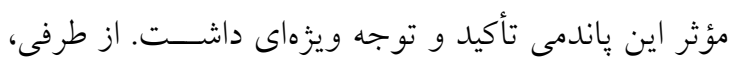

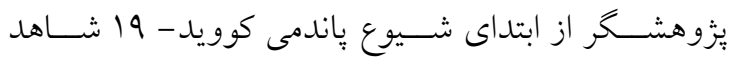

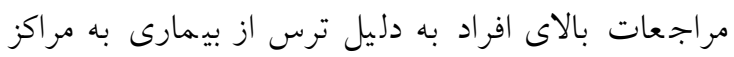

ميزان اضطراب در مراقبين بهداشتى زن بيشتر از مردان

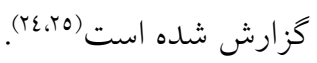
در مطالعاتى به جالشهاى مقابله با كوويد- 19 از ديدكاه

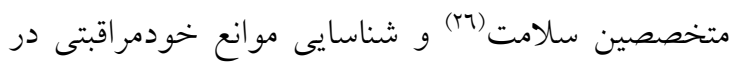

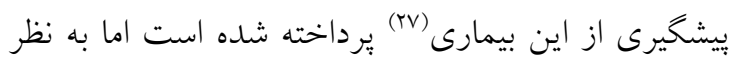

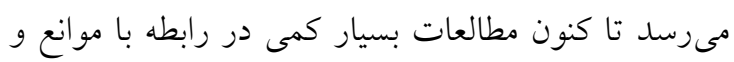

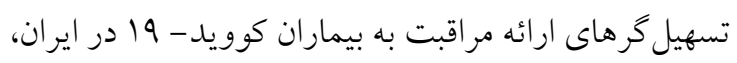

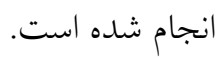
بر اساس يافتهاى مطالعه عليزاده و همكاران، كاركنان بخش درمان شرايط خاصى هميجون ماهيت ناشناخته بيمارى، تعداد بالاى مراجعات، مرى و مير بالا را تجربه

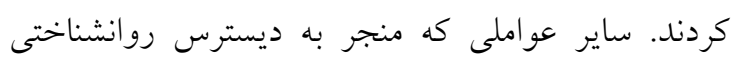

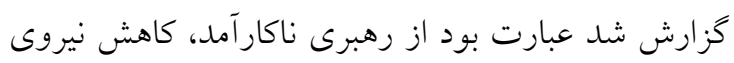

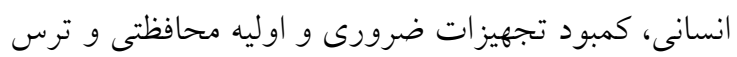

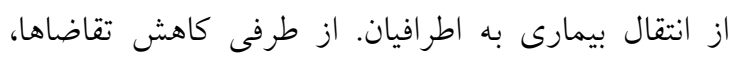

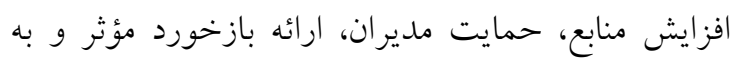

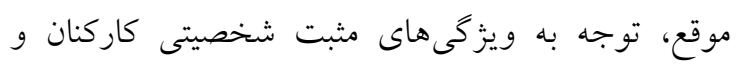

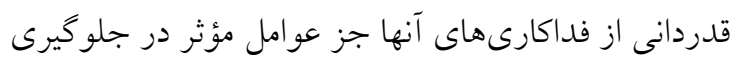

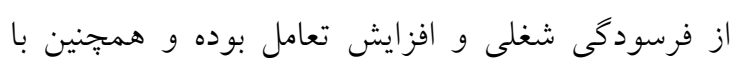

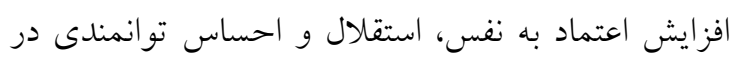

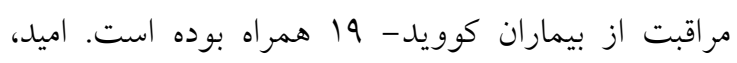

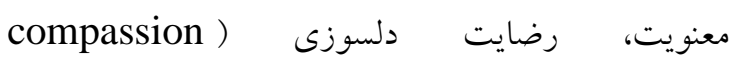

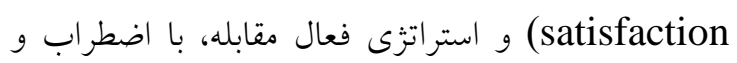
فرسودگى شغلى رابطه منفى داشت (T^). ساداتى و همكاران نيز در يكى مطالعه كيفى از تجربيات

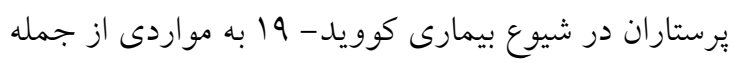

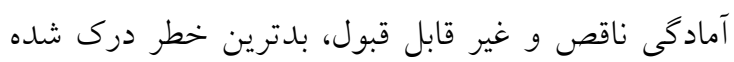

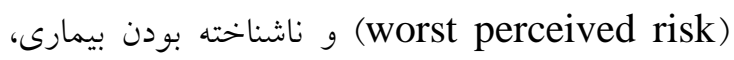

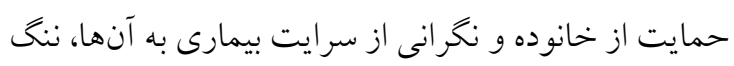
اجتماعى، تعهد و فدكارى اشاره كردند (19). يبامدهاى اشاره شده تأثيرى منفى بر كيفيت ارائه خدمات كاركنان داشــته اســت و به عنوان مانعى در مقابل ارائه

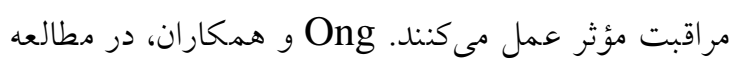

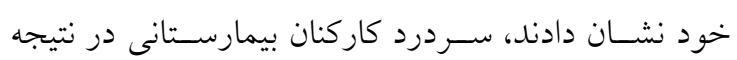


بوده، انجام شد. زمان هر مصاحبه بين 0 ع تا •ا ل7قيقه بود.

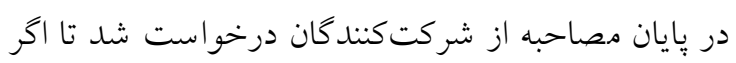

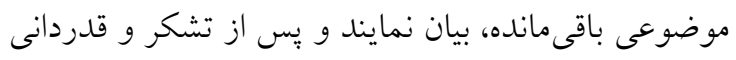

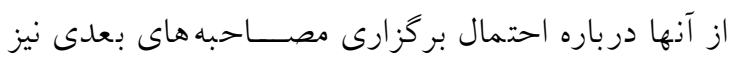
صحبت مى شد. هر جند با همه شركت كنندهها تنها يكبار

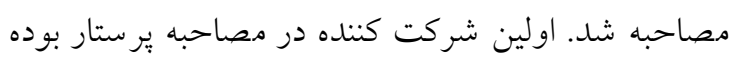

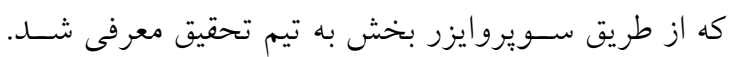

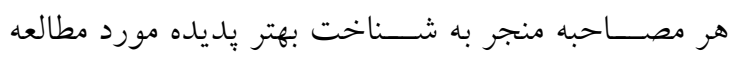

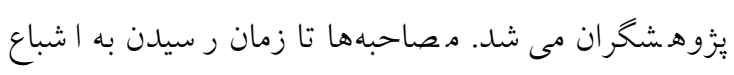

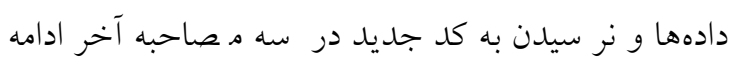

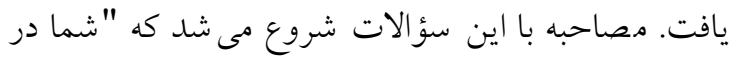

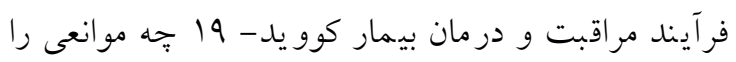

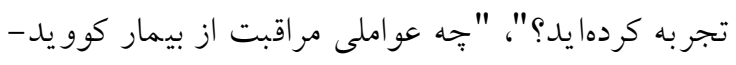

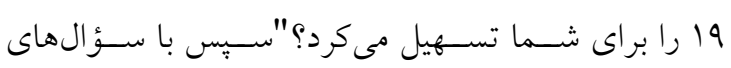
بيخيرى همجيون "لطفاً بيشتر توضسيح دهيد؟ مى توانيد در

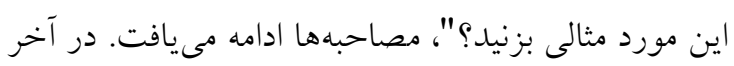

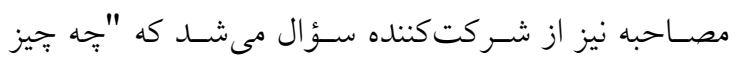

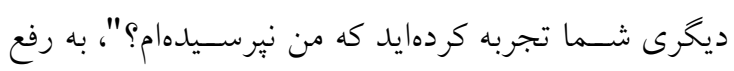

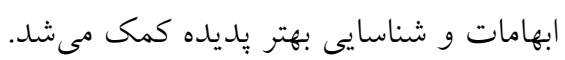
آناليز دادهها

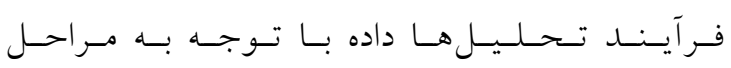

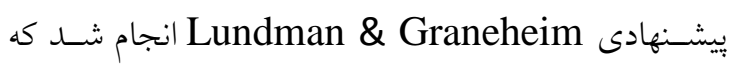

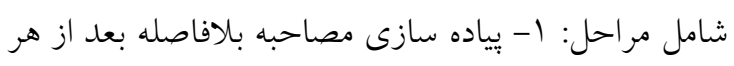

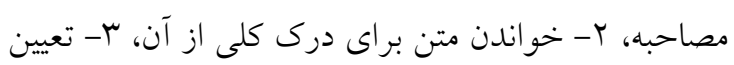

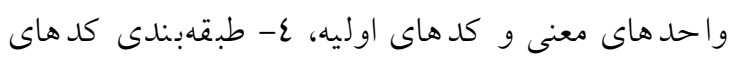

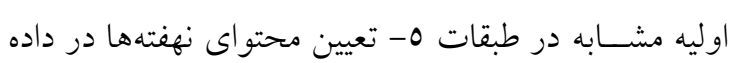

$$
\text { ها مى باشد (v) }
$$

در مطالعه حاضر بلافاصله بعد از انجام مصاحبه، محتواى

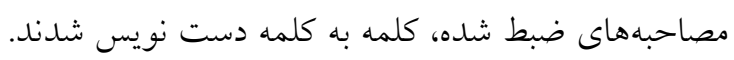

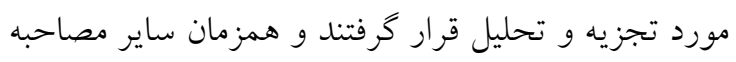

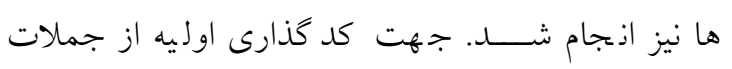

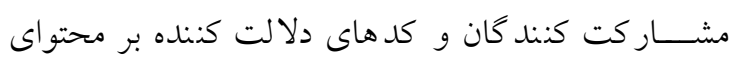

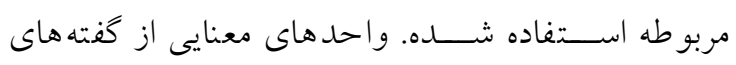
مشــاركت كنندكان در قالب كدهاى اوليه از مصــاحبهها
درمانى بوده و تعداد بالاى ابتلا به خصـوص در موجهاى

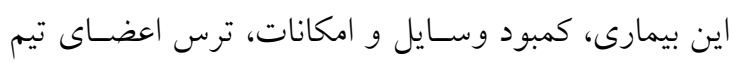

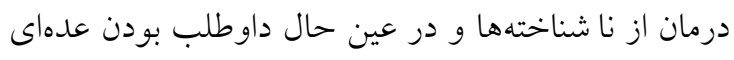

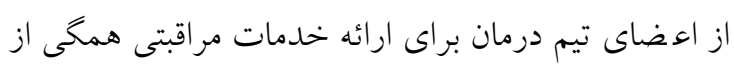

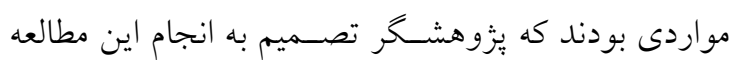
كرفت. دانشكاه علوم يز شكى تهران يكى از اولين دانشئاه

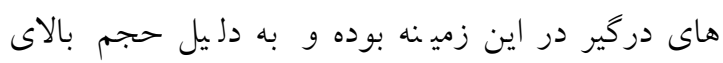

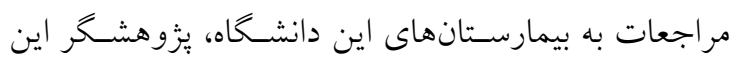

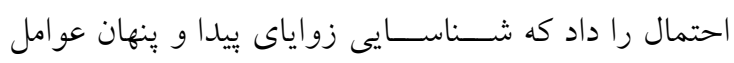

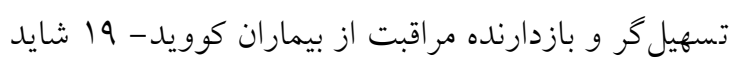

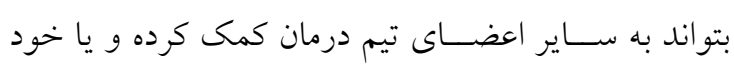

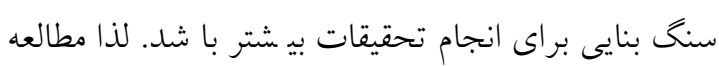

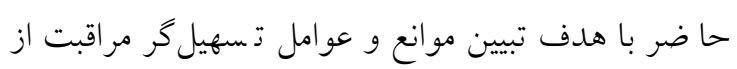

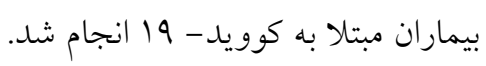

\section{روش بررسى}

مطالعه كيفى حاضــر با رويكرد آناليز محتواى عرفى از فوردي

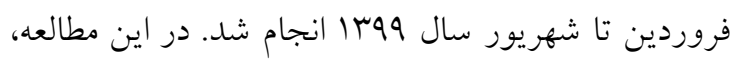

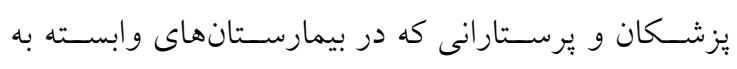
دانشــاه علوم يزشـكى تهران (مجتمع بيمارسـتانى امام خمينى(ره)، سينا، بهارلو، وليعصر و بيمارستان ياس) انجام تهري

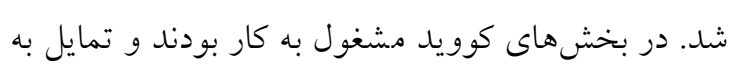

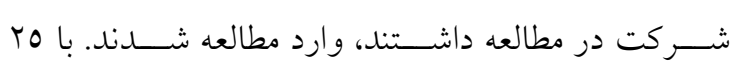

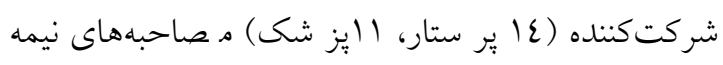

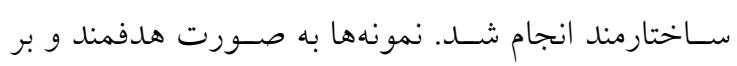

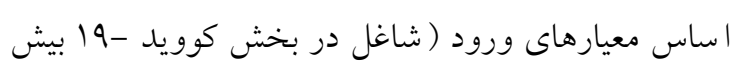

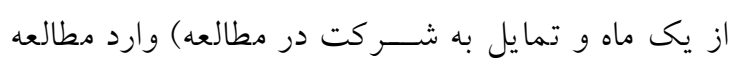

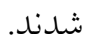
جمع آورى داده

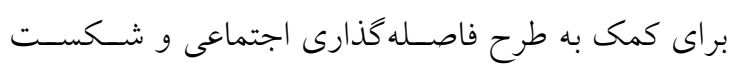

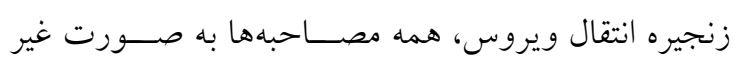
حضورى و با كمك Skype و Skat's APP در زمانى كه براى شركت كنند كان مناسب بود، انجام شد. مصاحبه هـا تو سط نويسنده مسئول كه در زمينه تحقيق كيفى با تجربه 
بر معرفى خود و توضــيح اهداف يزّوهش به مشـــاركت

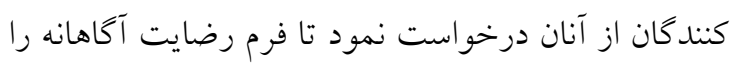

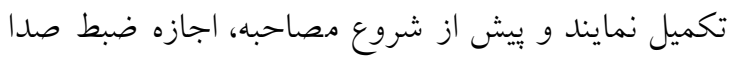

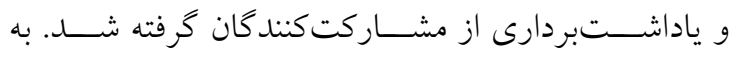
مشـاركت كنندكان اطمينان داده شــــ كه در هنگكام انتشـار

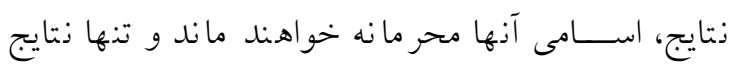

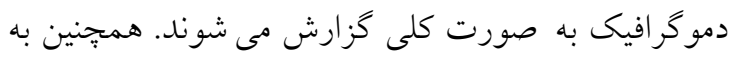

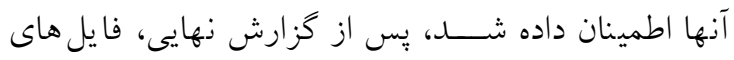
صوتى حذف خواهند شد و در صورت تمايل مى توانند،

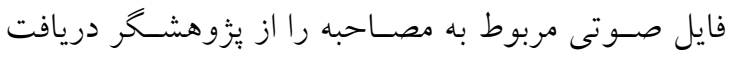

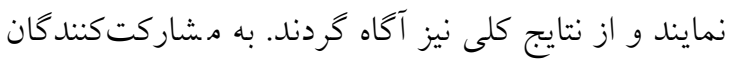

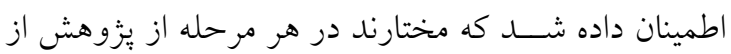

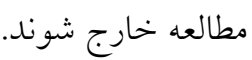

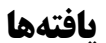

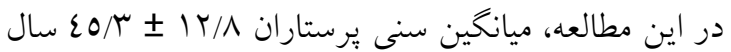

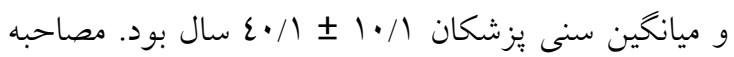
با rO برستار و ويزشك انجام شد كه .r نفر متأهل و 17

$$
\text { نقر زن بودند. }
$$

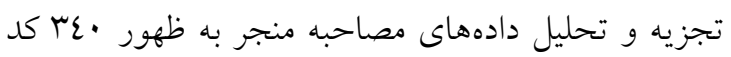

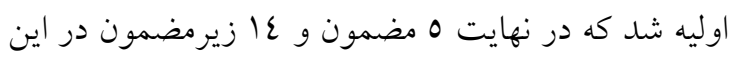
مطالعه ظاهر شد. فرهنگ، شمشير دولبه

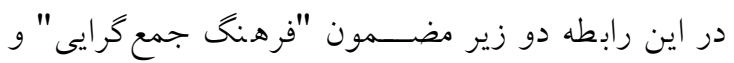
"فرهنگ ت سهيل گر " وجود دا شت. يز شكان و و بر بر ستاران شركت كننده در اين مطالعه اظهار داشتند كه فرهنگ حاكم

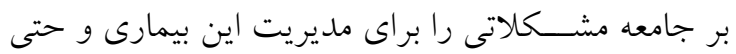

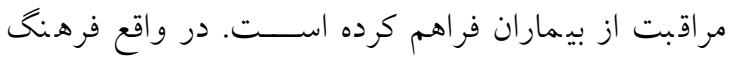

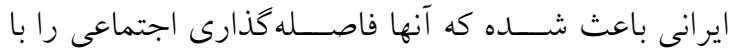
وجود هشدارهاى مكرر مسئولين وزارت بهداشت، رعايت

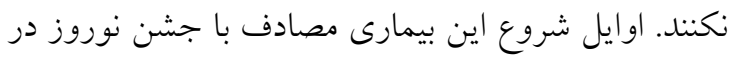

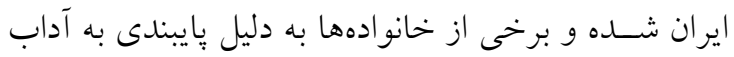

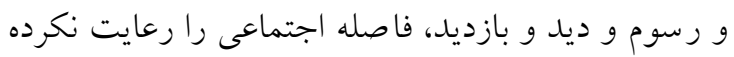

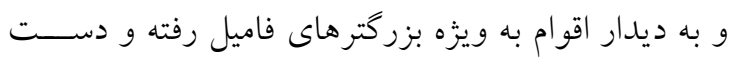

استخراج شدند. جندين بار هر كد بازخوانى شد و سيس

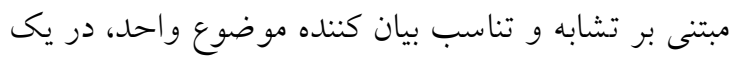

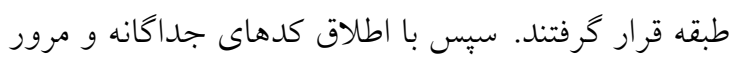

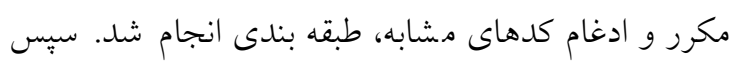

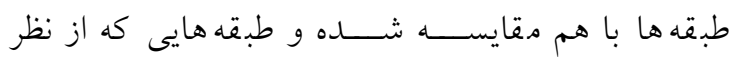

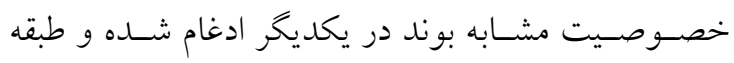

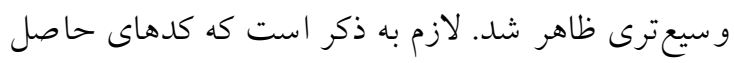
از تحليل دادهها تا مرحله زخحارش نهايى طرح بازنخرى و و

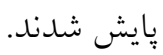

\section{استحكام دادهها}

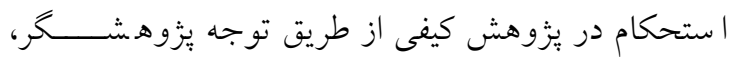

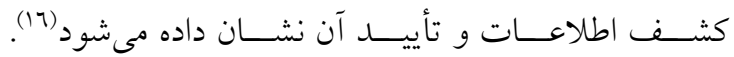

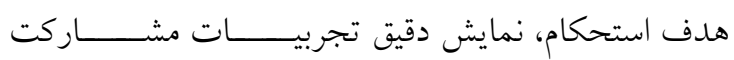

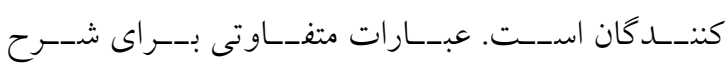

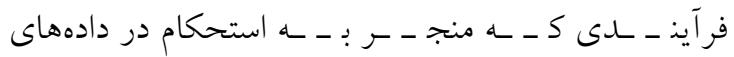

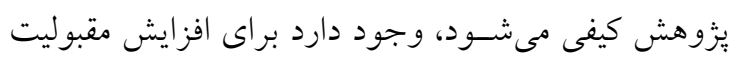

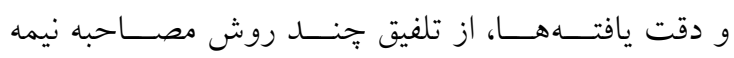

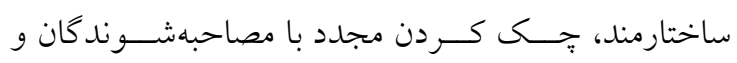

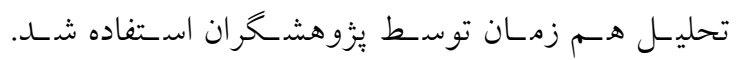

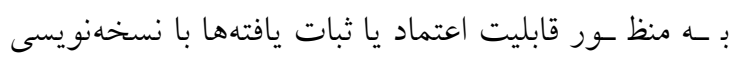

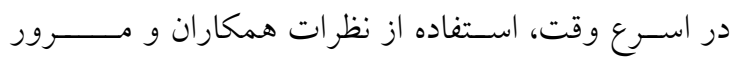

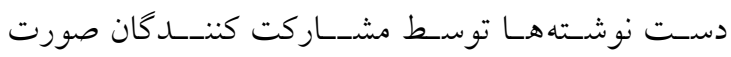

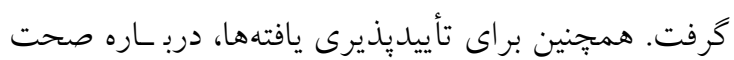

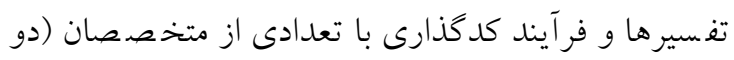

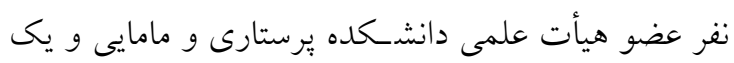

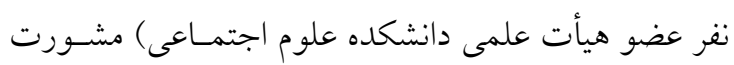

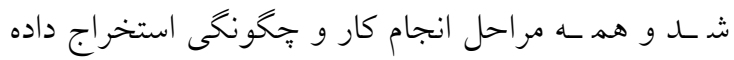

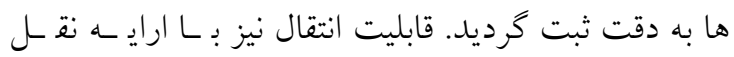

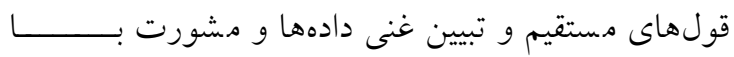

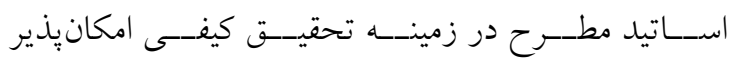

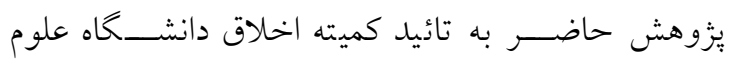

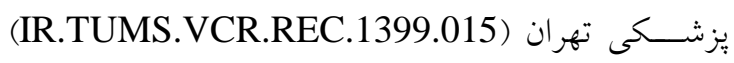

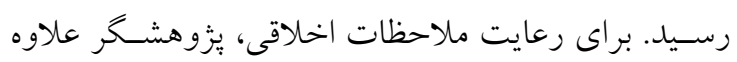


"اكى /ين مردم نبودند ما مى مرديم، اومان برامون لباس و

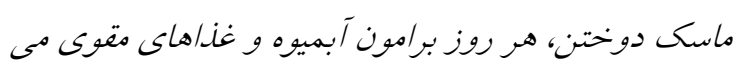

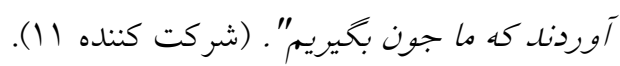

\section{عوامل فردى}

تيم درمانى به دليل ماهيت بيمارى نيز دغدغههايى داشتند. در واقع ماهيت انت شار سريع اين بيمارى براى تيم درمان يكى احساس ترس در خصوص ناقل بودن آنها ايجاد كرده بود. آنها ترس آن را دا شتند كه ناقل بوده و اين بيمارى را

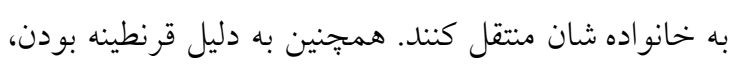

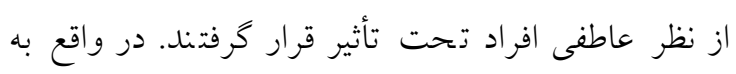

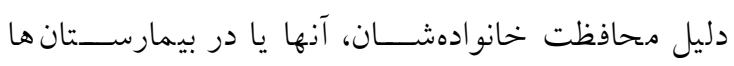
مى ماندند و يا فرزندان آنها به خانه بدربزرى و و مادربزرى

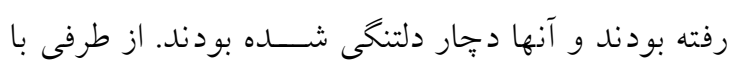

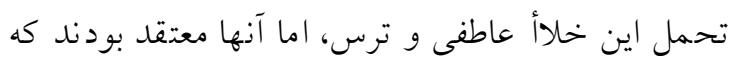
نبايد اين فشـار و اسـترس به بيماران منتقل شــود و نياز

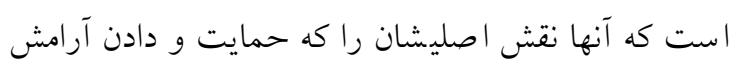
به بيماران اسـت را ايفا كنند. در واقع تفكر اينكه برستئار

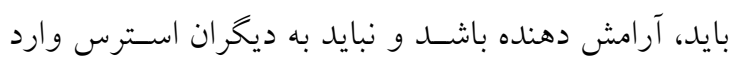

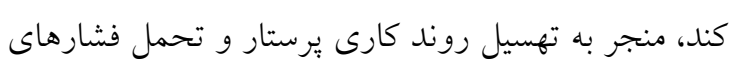
روانى و جسمى ناشى از شرايط سخت مى شد. در همين

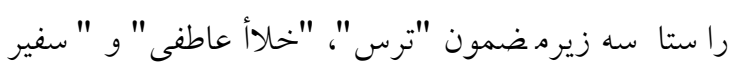

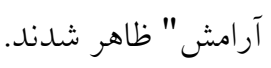

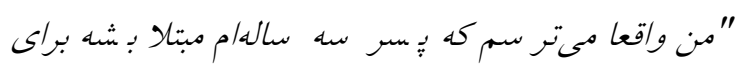

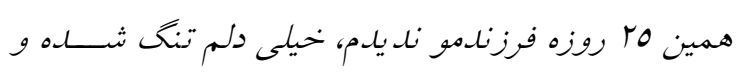

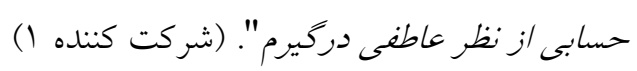

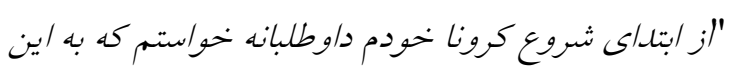

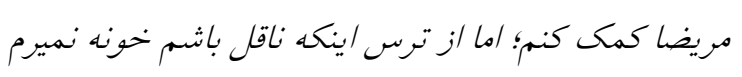

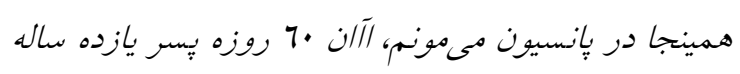

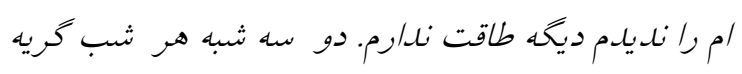

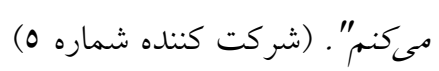

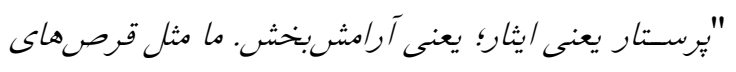

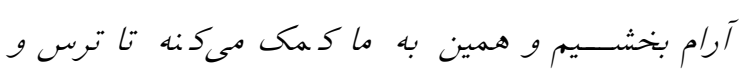

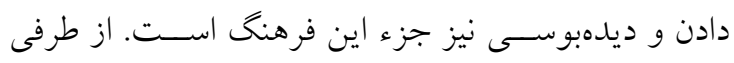

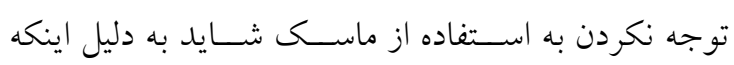

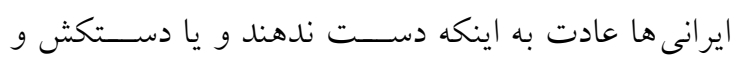

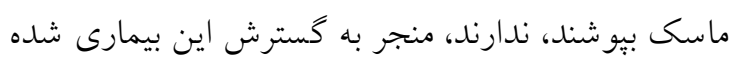

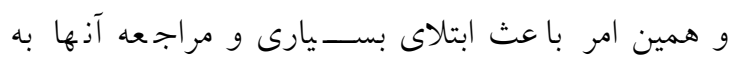

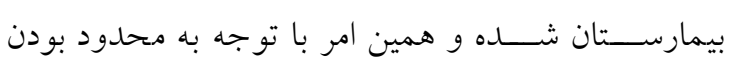

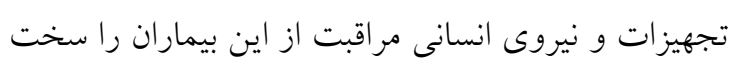

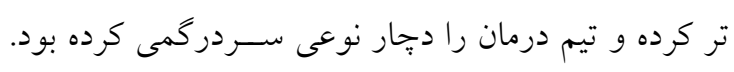

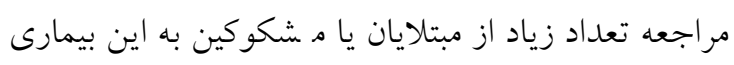

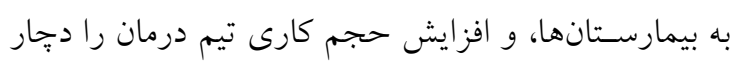

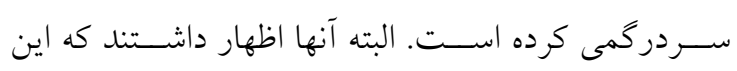
فرهنگ هميشه هم بد نيست، جرا كه ايرانى ها در فرهنگ

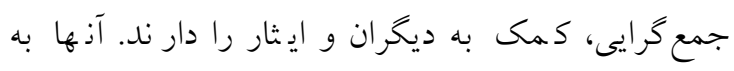

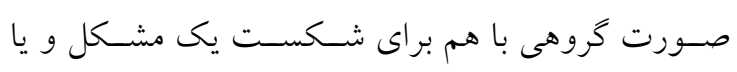

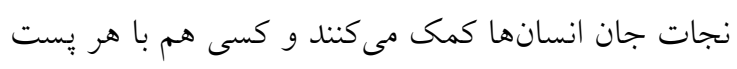

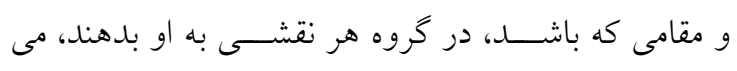

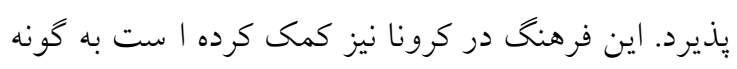

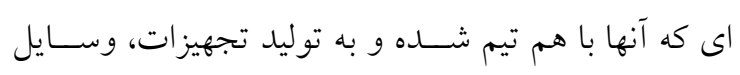

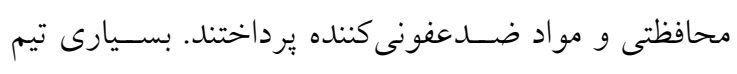

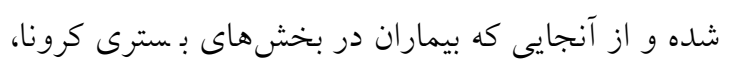

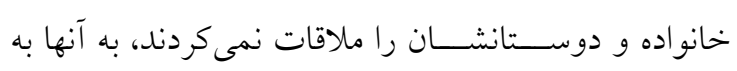

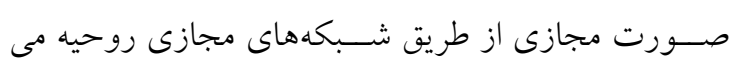

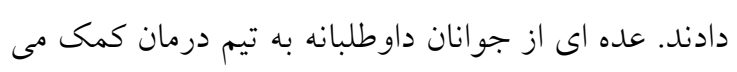

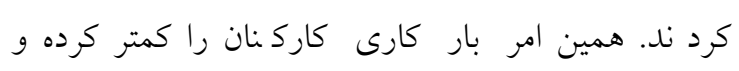
خستخى آنها را كاهش مى داد.

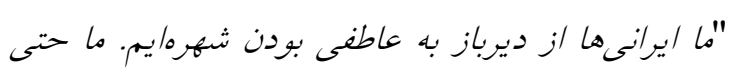

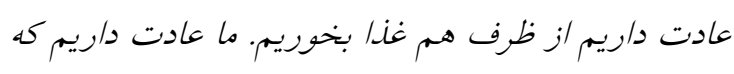

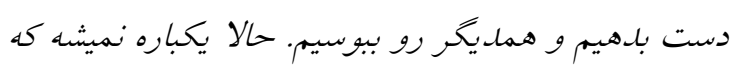

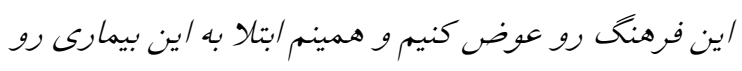

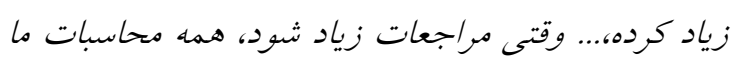

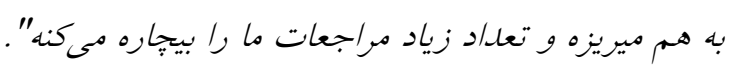

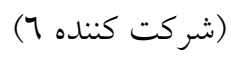


همكارى تيمى را بين اعضــاى تيم درمان دو جندان كرده

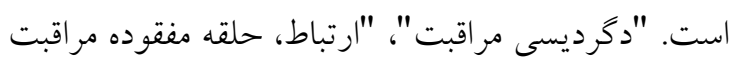

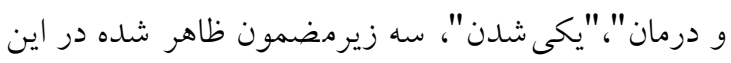
مطالعه هستند. "وقتى ماهيت بيمارى با يكى سرعت عجيب و غريب تغيير

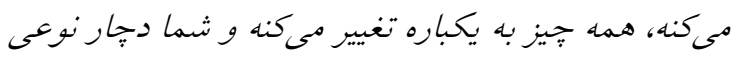

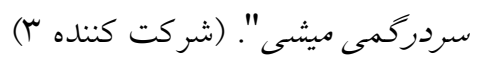

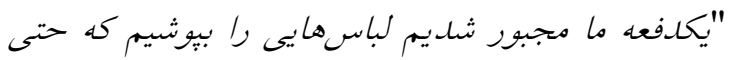

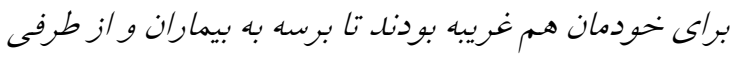
خودمون با خودمونم ديخه نمىتونيم حرف بزنيم. اينها واقعا /ذيتكنناه هستند ". (شركت كننده 9)

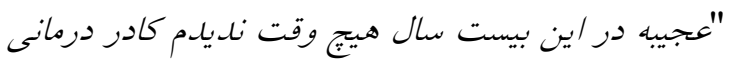
يكى بشن، ديخه معنى ند/شت كه هر كسى جه سمتى داره،

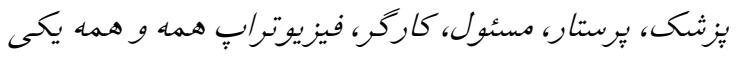

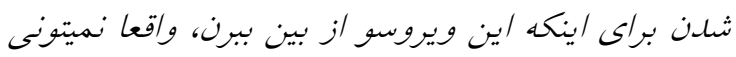
تشخيص بلدى كه كى جه بِّى و مقامى داره". (شركت

كننده r) (1)

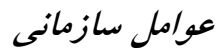
تيم درمان معتقد بودند دنيا با يكى شــوك ناءهانى مو اجه

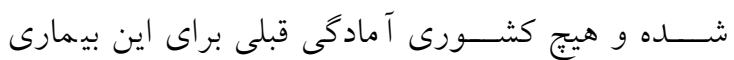

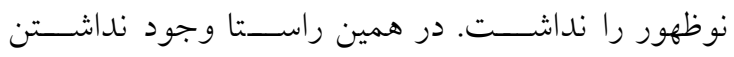
زيرسـاختهاى لازم و كمبود تجهيزات و نيروى انسـانى، همخى از مهمترين جالشهاى تيم درمان بوده اسـت. در

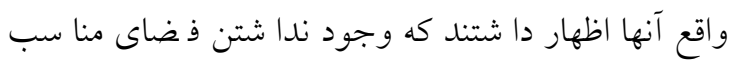
براى مراقبت از اين بيماران، كمبود نيروى انسـانى و نبود امكاناتى همجيون دارو، دستخاه ونتيلاتور و ساير تجهيزات

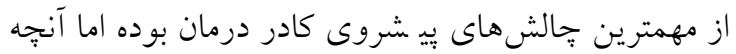
كه به آنها كمكى كرده تا بتوانند در اين فرآيند مقاومت داين كنند، حمايت از سوى مديران بيمار ستانى، معاونت درمان

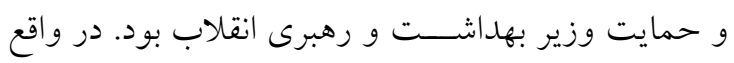

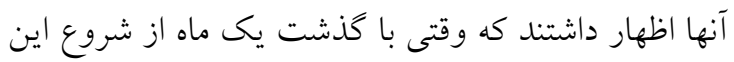

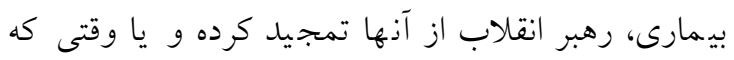

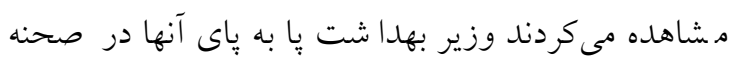

اضطرابمونو بنهان كنيم و به ديخران كمك كنيم". (شركت

كننده

\section{تغيير در رويكرد مراقبت}

ماهيت اين بيمارى و اسـتفاده از وسـايل حفاظتى توسطـ يرسنل، رعايت فاصله، تغيير در نحوه ارتباط با بيمار، تغيير در تعاملات حرفهاى، احســاس فقدان قدرت در مديريت اين ويروس همخى از جمله جالش هاى تيم در مان در مراقبت از اين بيماران بوده است. در واقع كاركنان درمانى ملزم به اسـتفاده از تجهيزات محافظت فردى در برابر فرد مشكوى يا مبتلا مىباشند. وسايل حفاظت فردى و احتياط نسبت به اين بيمارى شامل استفاده از ماسك N95، كان، دسـتكش، كلاه، عينك و جّكمه و بسـترى بيمار در اتاق ايزوله و با فشار منفى اعلام شده است. حجم كارى بالا، يو شيدن لباس هاى حفاظتى، رعايت فاصله كذارى با بيمار،

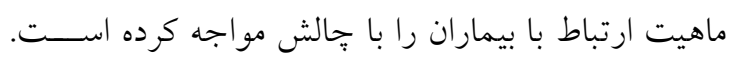

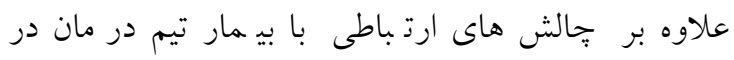
برقرارى ارتباط با همديخر نيز مشـكلاتى را تجربه كردند.

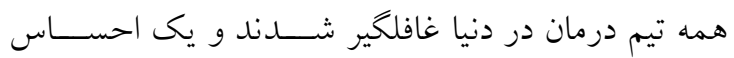

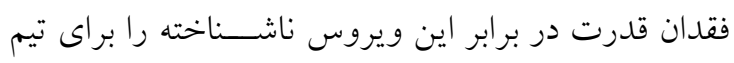

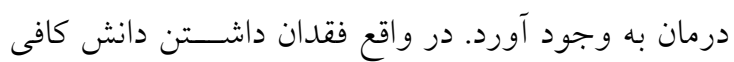
ذسبت به اين بيمارى، نا شناخته بودن ذشانهها و عوارض

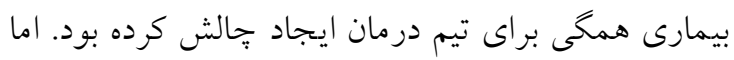
اين ويروس يك تغيير ديخر نيز در تيم درمان ايجاد كرده

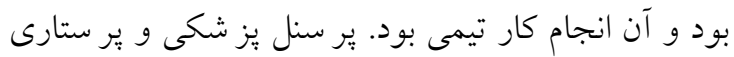

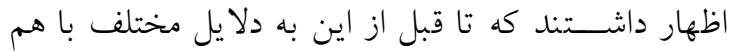

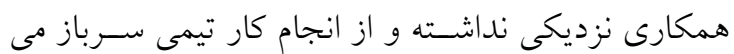

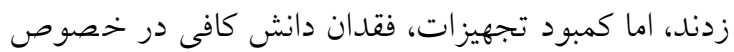

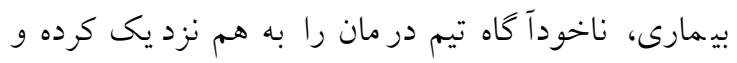

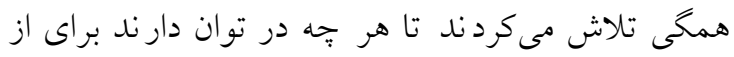
بين بردن اين بيمارى بكار بخيرند. اين تغيير در ارتباط با هرديا

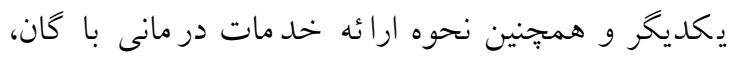
لباس محافظتى، عينك و ساير و سايل حفاظتى يك تجربه جديد براى بيماران و تيم درمانى بوده و از طرفى روحيه 
فرد آزاردهنده بود و باعث خ ستخى وى در امر مراقبت از

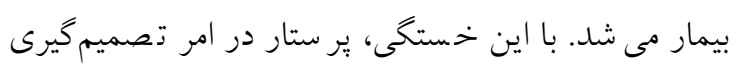

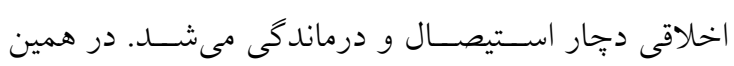

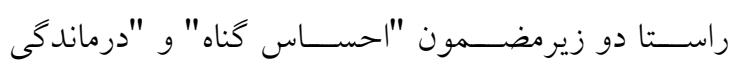
اخلاقى " براى تيم درمان ظاهر شد. رئر

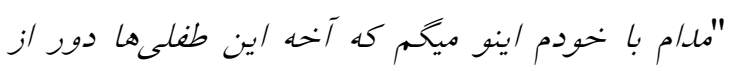

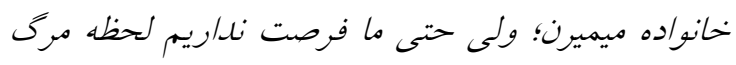

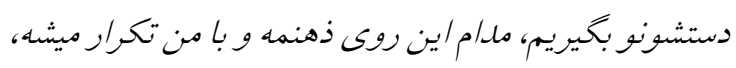

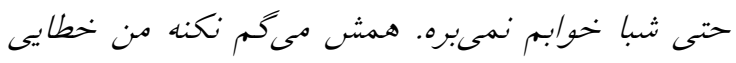

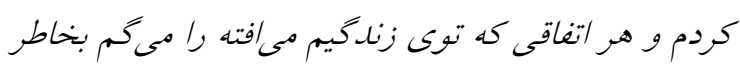
كم كارى يا اشتباه براى مر/قبت /ز /ين ها بوده ". (شركت

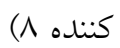

"درمونله شدم، من حتى به مريضم نميكم كه تو كجا

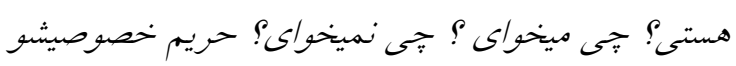

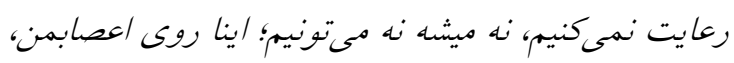

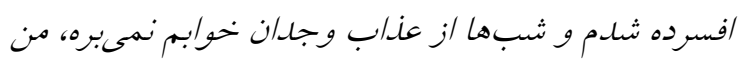
بعل /ز /ين بحران /ستعغامو مىنويسم. جون ونس واقعا كلافه

شدم و نمىدونم بايد جيكار كنم". (شركت كننده با ).

\section{بحث و نتيجه تيرى}

در راســتاى هدف مطالعه عوامل مختلفى نظير فرهنخ،

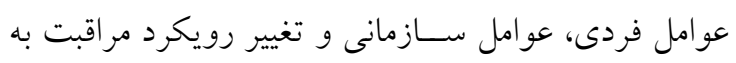
عنوان موانع و تسـهيل كنندهاى مراقبت از بيماران كوويد عرديد

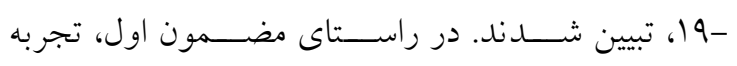

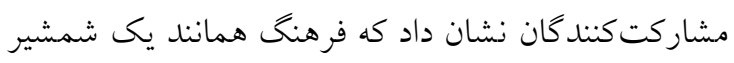

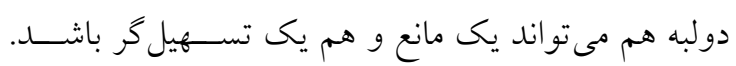

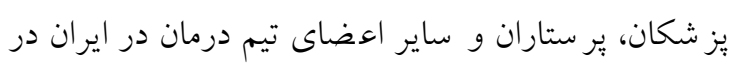

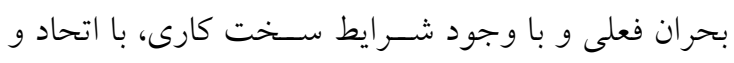

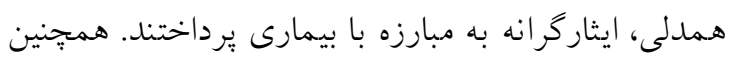

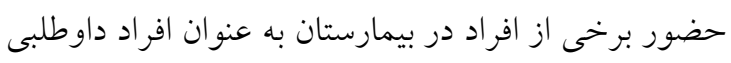
كه به تيم درمان كمك مى كردند، بار كارى تيم درمان را ران

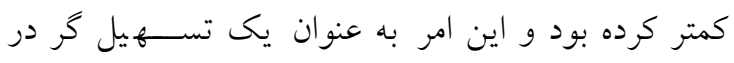

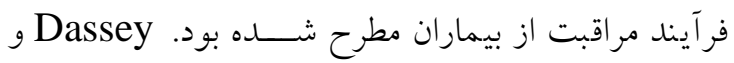

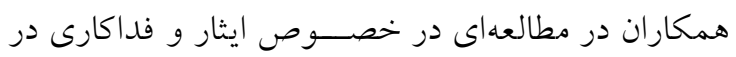

ا ست روحيه كرفته و به كار ادامه مى دادند. در اين را ستا،

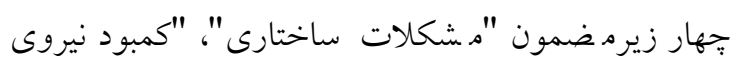

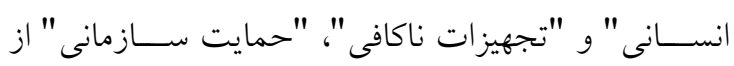
مهمترين موانع تيم درمان براى ارائه مراقبت بوده است.

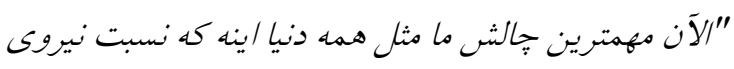

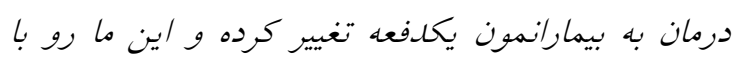

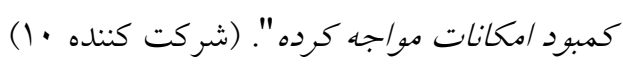

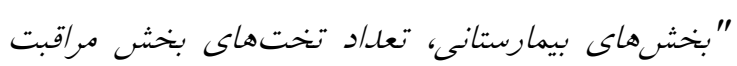

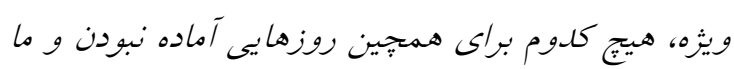

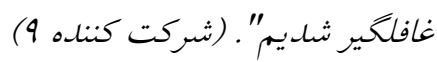

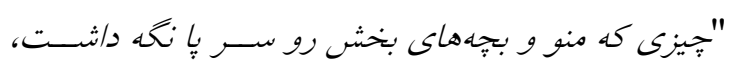

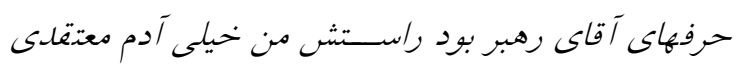

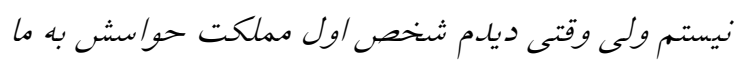

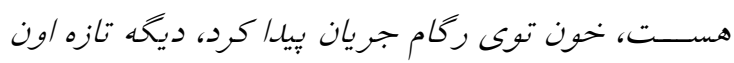

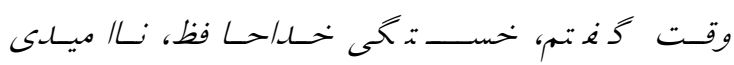
خداحافظ."(شركت كننده ع) يريشانى اخلاقى شركت كنند كان در اين مطالعه اظهار داشتند در بسيارى از

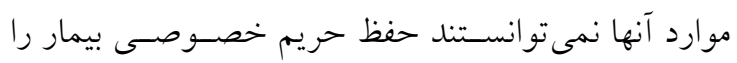

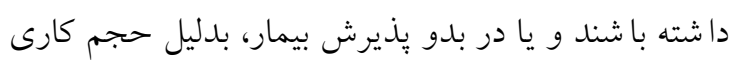

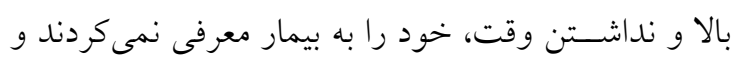

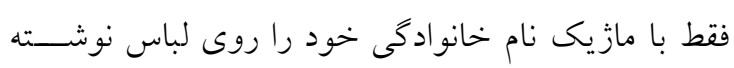

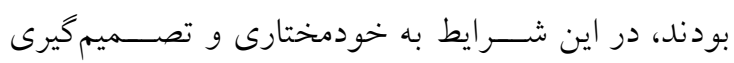

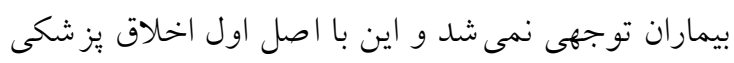

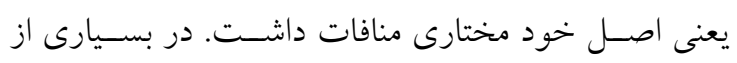
موارد وقتى بيمار مبتلا به كوو يد- 9 ادر لحظات انتهايى مناري

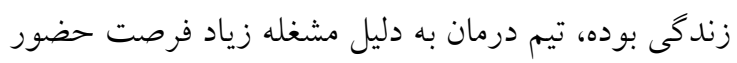

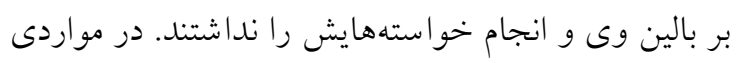

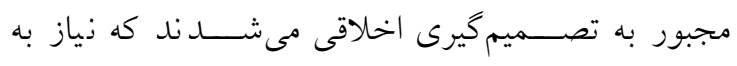

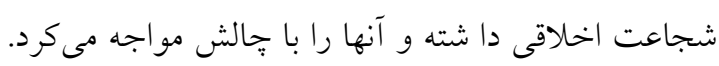

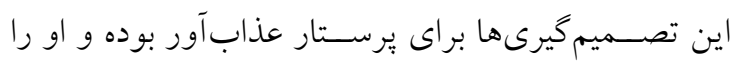

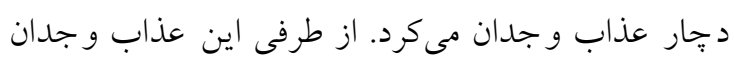

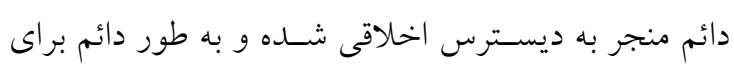


اسـت شـناخت اين رفتارها در ارائه آموزش مؤثر و نهايتاً

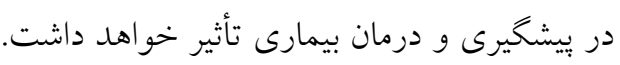

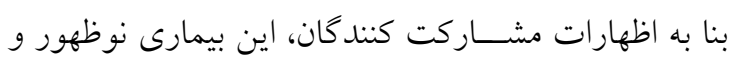

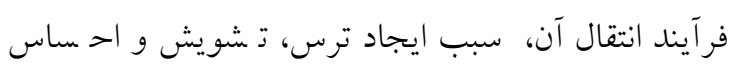

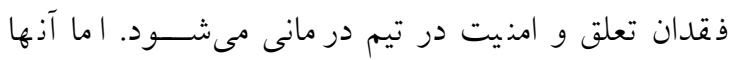

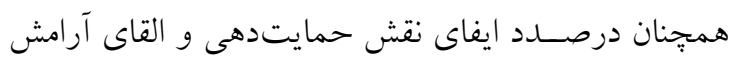

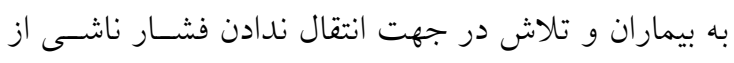

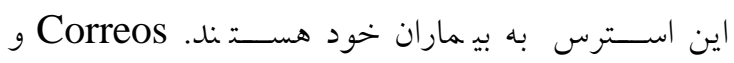
Magneye

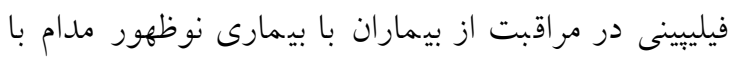

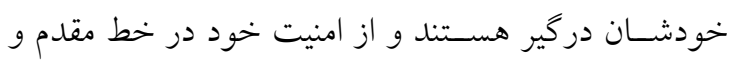

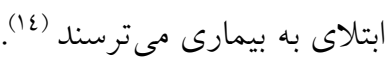

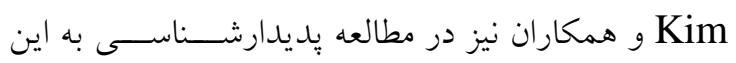

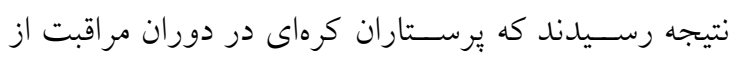

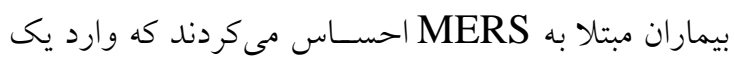

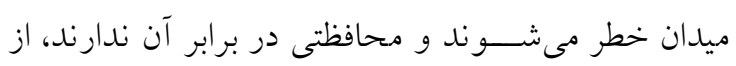

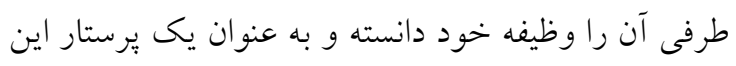

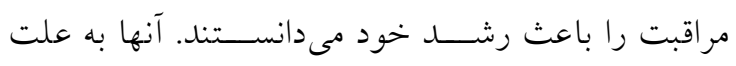

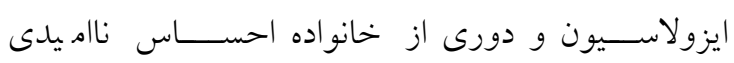
داشتند (10). مطالعه حا ضر ذشان داد كه رويكرد مراقبت از بيماران در

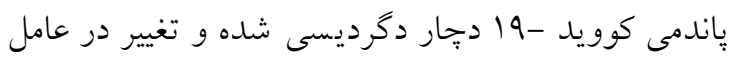

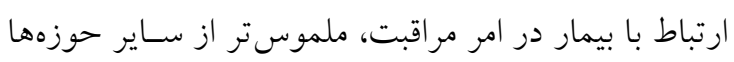

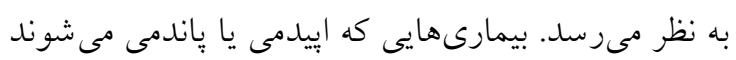

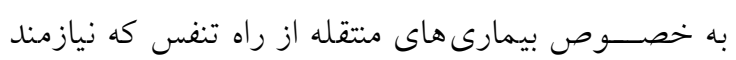
ا ستفاده از و سايل حفاظتى است، ارتباط با بيمار، خانو اده

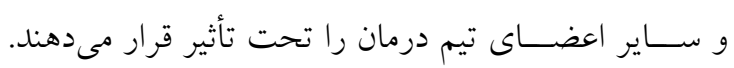

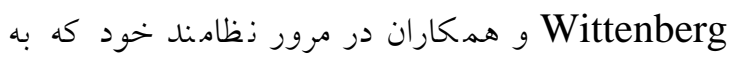
بررسى فرصست هاى بهبود ارتباط مر اقبين بيماران كوويد

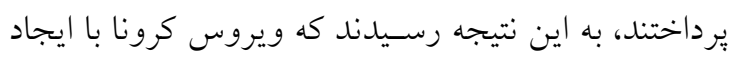

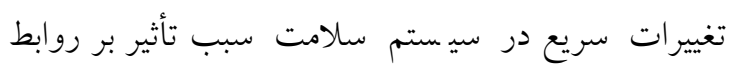

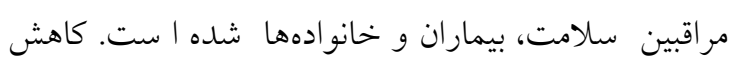
كانال هاى ارتباطى، فقعدان حضــور خانو اده ها در كنار

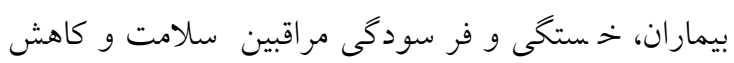

فرآيند مراقبت از بيماران در مناطق مختلف كشـــور جين

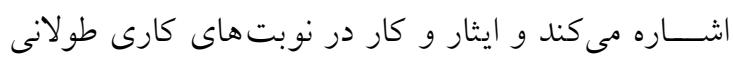

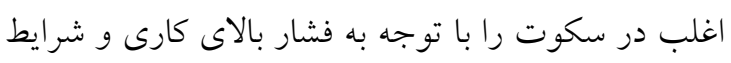

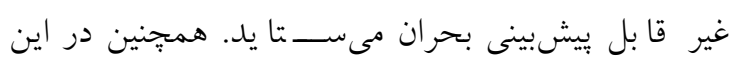

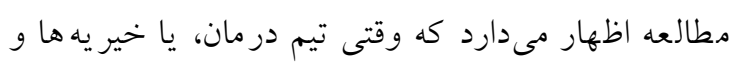

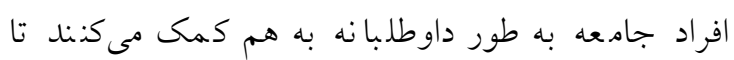

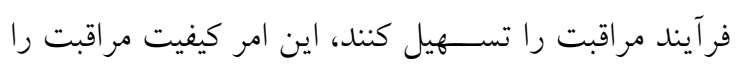

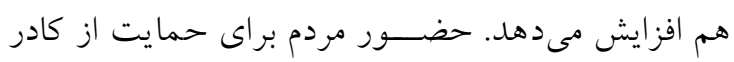

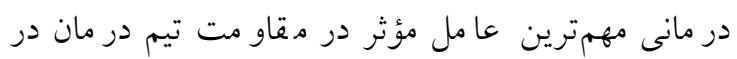

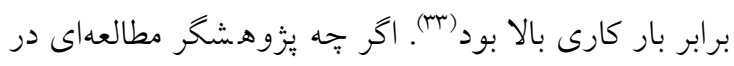
خصـوص اهميت فرهنگ در بيشــيرى، مراقبت و درمان

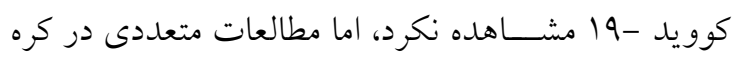

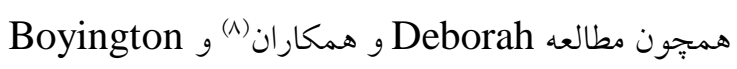

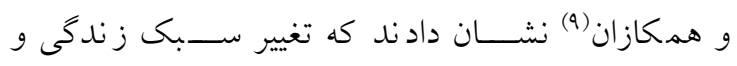

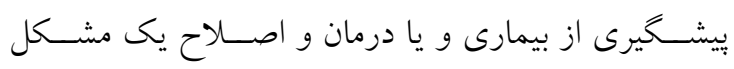

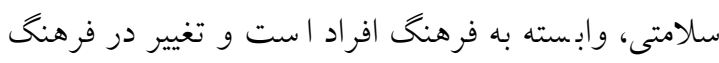

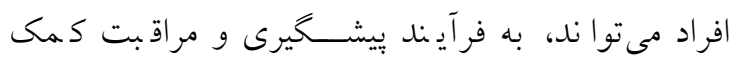
كند (11."). هر فرهنكى داراى ديد كاه ها، رفتارها و و عقايد

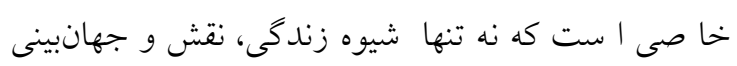

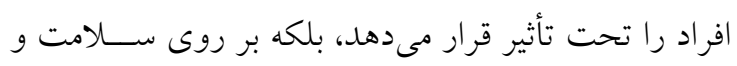

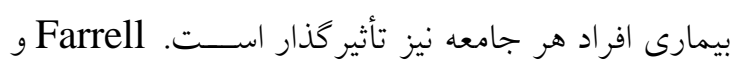

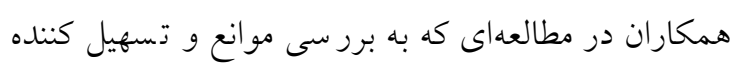

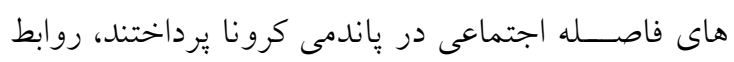

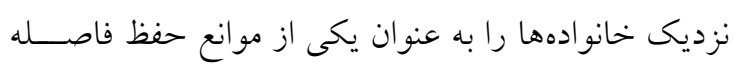

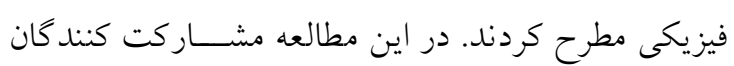

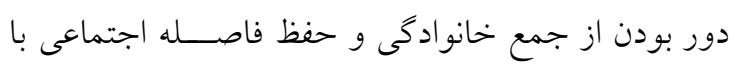
دو ستان نزديك را به عنوان سخت سترين تجربه اين دوران

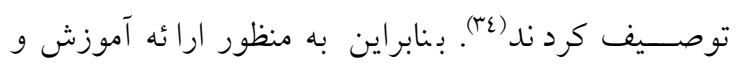

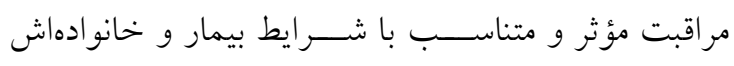

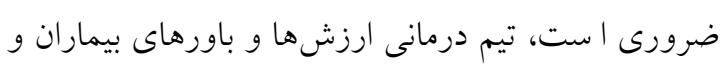

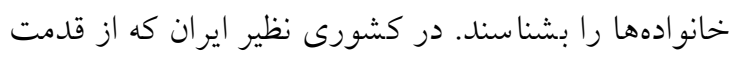

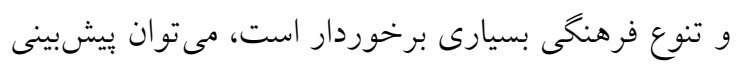

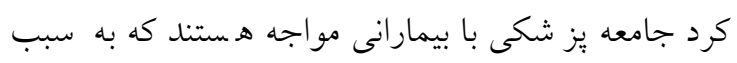

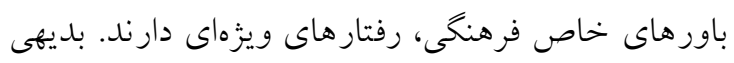


مناسـب همجيون بلندى صـدا، لحن، لهجه، سـرعت كلام،

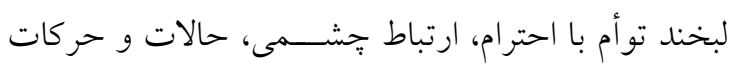

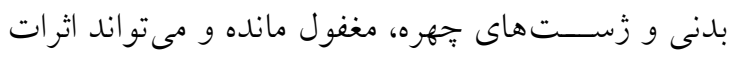

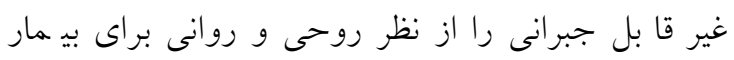

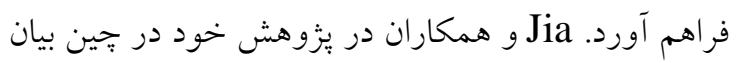
داشتند كه شيوع گسترده بيمارى و مملو شدن بيمار ستان

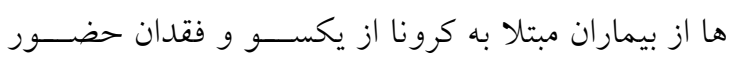

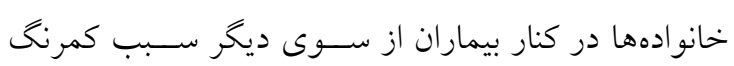

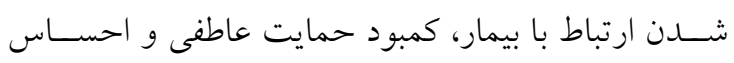

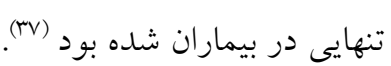
در مضــمون عوامل ســازمانى، شـــركت كنتد كان كمبود

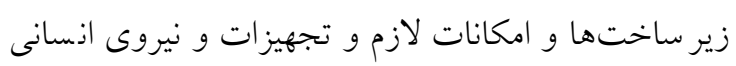

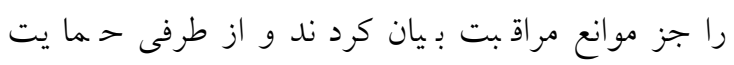

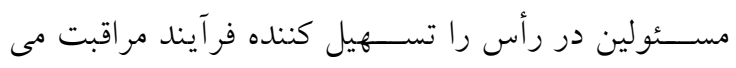

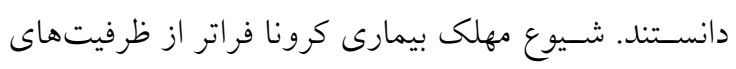
موجود نظام سلامت در بسيارى از كشورها بوده است و

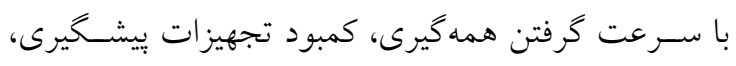

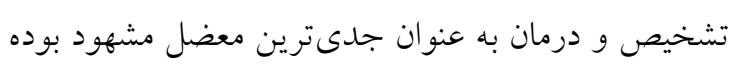

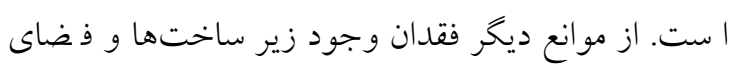

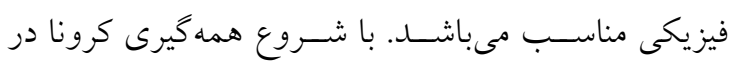

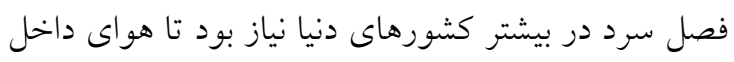

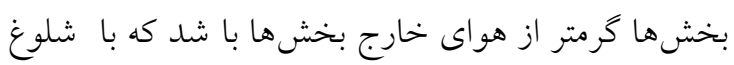

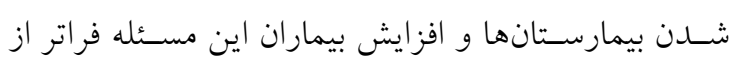
توان عملياتى بسيارى از مراكز سلامت گزارش شده است.

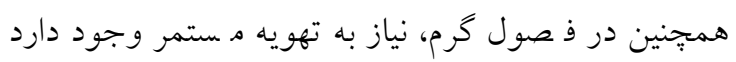

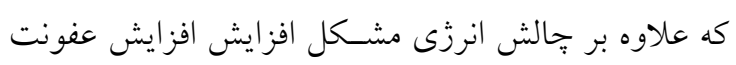
هاى فرصت طلب نيز مطرح است در اين راستا Palagyi

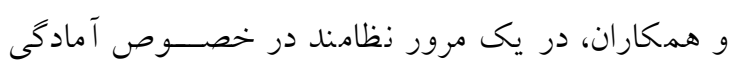
كشورهاى جهان سوم و در حال تو سعه در برابر بيمارى

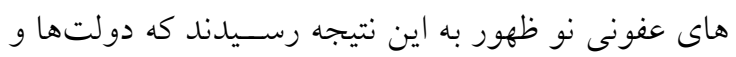

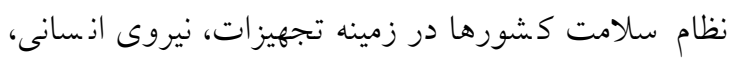

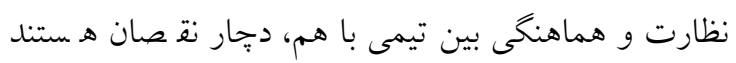

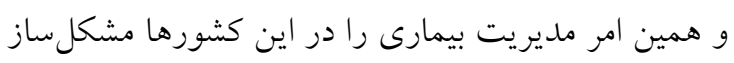

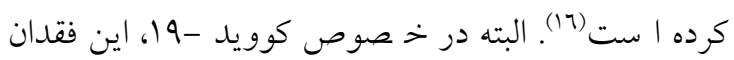

مراقبت بيمار محور از موانع ارتباط صسحيح در اين دوران بود2(ro) همكارى تيمى در ميان كاركنان درمانى نيز در ميان يافتهها

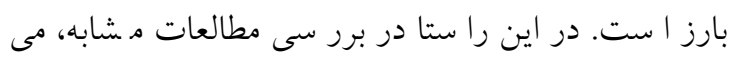

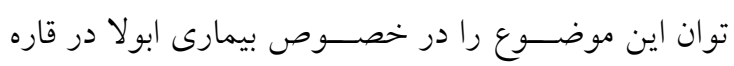

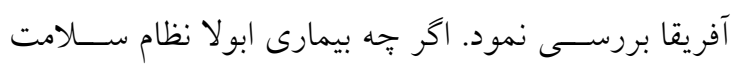

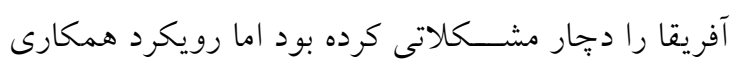

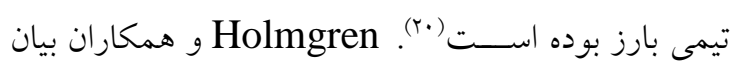

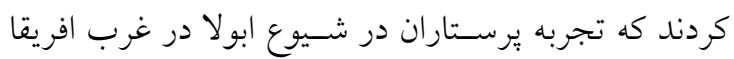

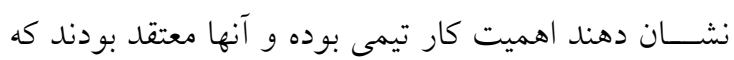

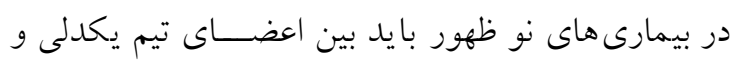
وحدت وجود داشـته باشـــ تا آنها بتوانند بيمارى را مهار

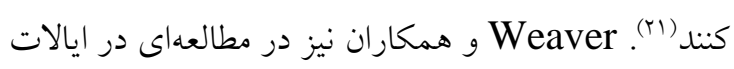

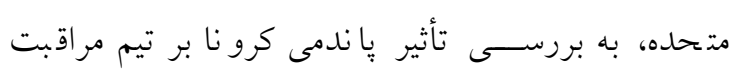

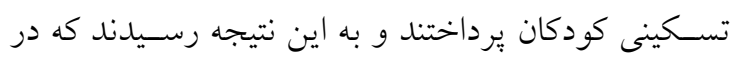

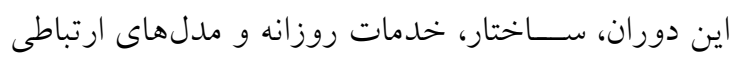

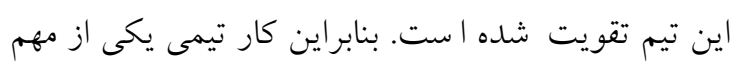

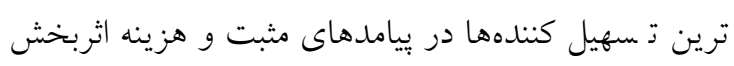
در محيطهاى سازمانى مختلف و نيز در تعامل افراد با هم در محيطهاى برخطر مىباشد (MT).

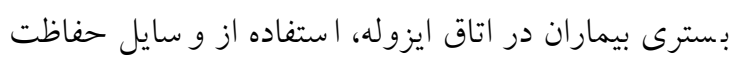
فردى (شامل ماسك، كان، دستكش، كلاه، شيلد)، رعايت

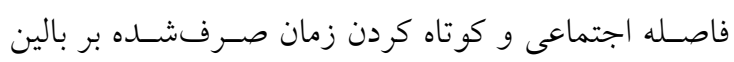
بيمار، يكى از مهمترين حقوق بيمار يعنى برقرارى ارتباط

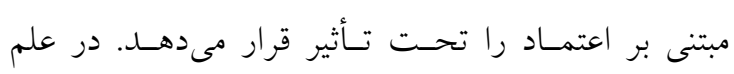

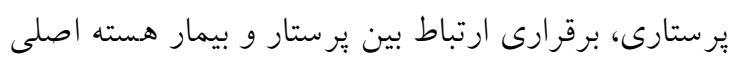

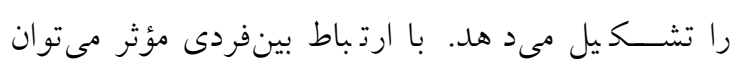

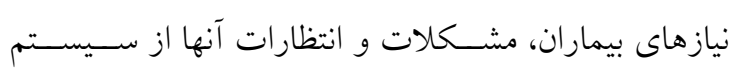

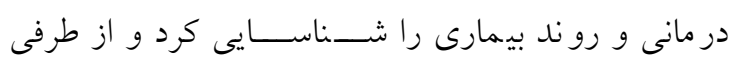

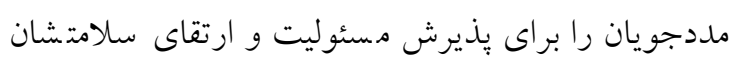

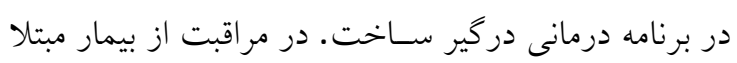

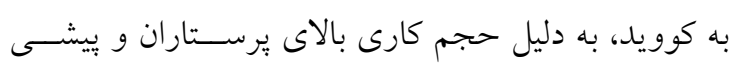

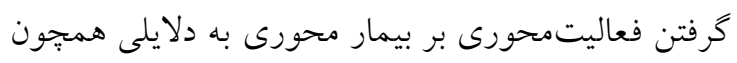

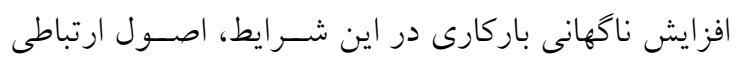


مهم ترين محدوديت اين مطالعه عدم مصاحبه حضورى به دليل رعايت فاصله گذارى اجتماعى بود. شايد اخر مصاحبه ها حضورى بود، تجربيات عميقترى را مى شد، درى كرد و حالات فيزيكى افراد را هم درى نمود.

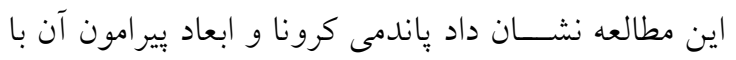

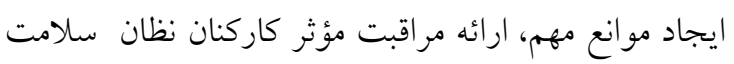
به بيماران دركير با بيمارى كوو يد- 19 را با تهلد يدات جدى مواجه سـاخته اسـت. فرهنخ جامعه اير انى همانند يك شم شمير دو لبه عمل كرده بود و در مواردى به دليل فقدان اسـتفاده از ماسـك و يا ديد و بازديد، ابتلاى افراد افزايش بِيدا كرده بود و از طرفى افراد با روحيه ايشار و فداكارى با همدلى سعى در رفع كمبودها داشتند. همجنين

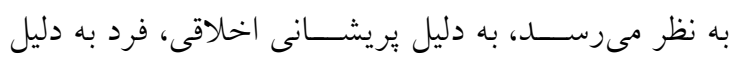

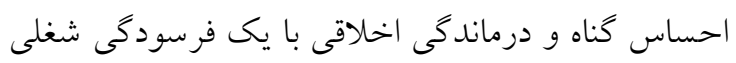
مواجه شــده و در دراز مدت اين فرســودگى به نفع نظام

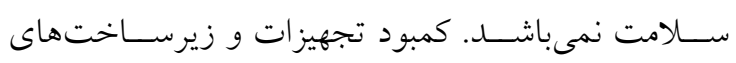
مناسـب در يُى اين باندمى و در عين حال اسـتفاده از اين تجهيزات مىتواند، مانعى مهم در ارائه مراقبت مؤثر تلقى

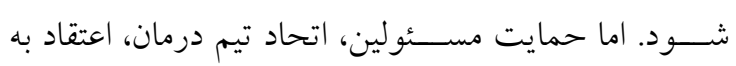
اينكه يرســتار بايد آرامش بخش باشــــ، همخى از عوامل

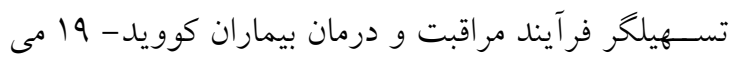
باشد. به نظر مىرسد، شايد لازم باشد كه مسئولين حمايت

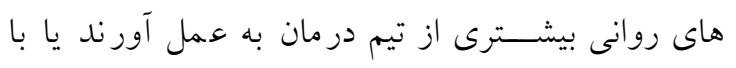
استخدام نيروهاى تازه نفس و كاهش بار كارى تيم درمان، به آنها يك دوره ريكاورى بلدهند. همجينين كمك كرفتن

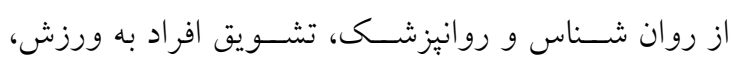
مديتيشـن، و موسـيقى مىتواند در تقويت نيروى انسـانى شاغل در بيمار ستانها كمك كننده با شند. هـ سئولين بايد براى افزايش تاب آورى كادر درمان در بِديدههاى نوظهور برنامهريزى كنند. به نظر مىرســ، انجام مطالعاتى مسـتقل در زمينه نقش فرهنگ در مديريت بيمارى در سطح جامعه لازم باشــــ. تلاش براى تغيير فرهنخ افراد جامعه بســيار

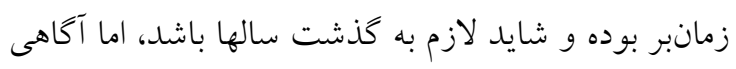

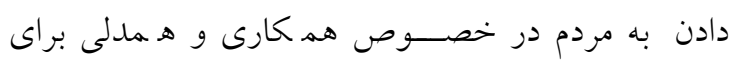

آمادكى تنها مختص كشـورهاى جهان سـوم نيسـت و در حال حاضــر حتى بيشــرفتهترين كشــورهاى دنيا نيز در مديريت اين بيمارى با كمبود امكانات مواجه بوده و دجار

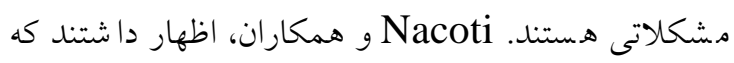
اكر مراقبت جامعه محور ذ شود با اين حجم از بيماران و

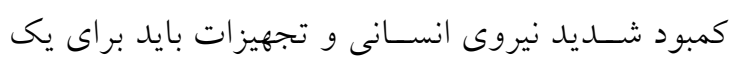

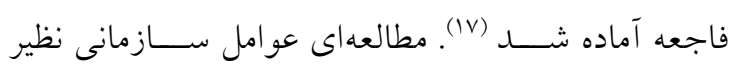
كمبود تجهيزات حفاظتى، فقدان آمادكى كافى در ارائه خدمات به مراجعه كنندگان، تغيير سريع اطلاعات، فقدان دســترســى به اطلاعات به روز، فقدان وجود داروهاى اخت صا صى بيمارى و كمبود تجهيزات مراقبتهاى ويزه به به روزئ نظير تخت و ونتيلاتور در بحران كرو نا مســبـ ايدجاد

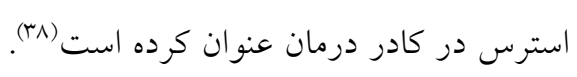
در خصوص مضمون بريششانى اخلاقى كه به عنوان يكى از موانع مراقبت از بيمار كوويد -19 با دو زير مضــمون احساس گناه و درماندگى اخلاقى مطرح شد. William و همكاران اظهار داشـتند كه يريشـانى اخلاقى احتمالاً در بحرانهاى حاد مراقبت هاى بهداشــتى رخ مىدهد، زيرا توانايى ارائه مراقبت بهينه مطلق نبوده و همين امر باعث

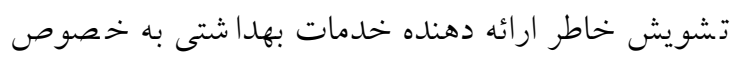

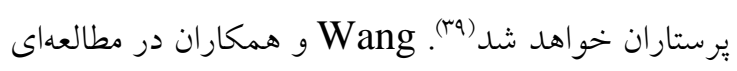
در تجين، درخصوص يريشانى اخلاقى اءضاى تيم درمان در طى بيمارى كوويد -991، اظهار داشتند كه وقتى اعضاى تيم درمان نمى توانند مراقبت با كيفيت تعريف شــــه را بـ به

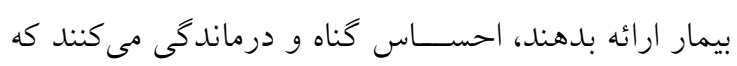
اين احســاس مىتواند منجر به يريشـانى اخلاقى شــده و

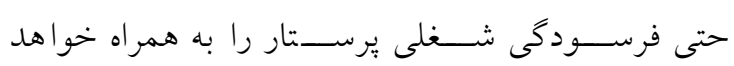

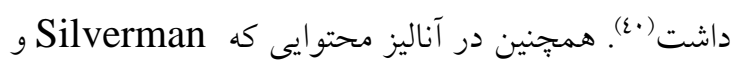

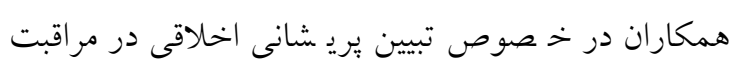

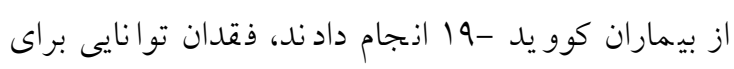

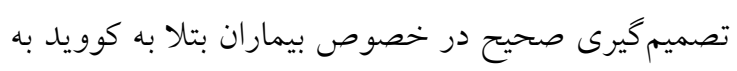
خصــوص در بـحث توزيع عادلانه خدمات و يا ارائه

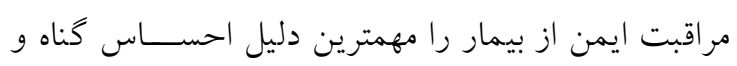
عذاب وجدان بيان كردند (1). 


$$
\begin{aligned}
& \text { تقدير و تشكر }
\end{aligned}
$$

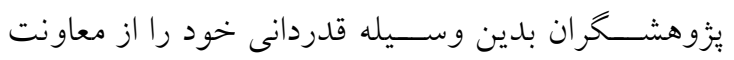

$$
\begin{aligned}
& \text { يزوهـشى دانشكاه علوم يز شكى تهران و شركت كنند ئان } \\
& \text { در اين مطالعه اظهار مىدارند. }
\end{aligned}
$$

\section{References}

1. Parchment $\mathrm{J}$, Andrews D. The incidence of workplace bullying and related environmental factors among nurse managers. JONA: J Nurs Adminis. 2019;49(3):132-7.

2. Garosi E, Mazloumi A, Kalantari R, Vahedi Z, Shirzhiyan Z. Design and ergonomic assessment of an infusion set connector tool used in nursing work. Applied ergonomics. 2019;75:91-8. [Persian]

3. Hoonakker PL, Carayon P. Work system barriers and strategies reported by Tele-intensive care unit nurses: a case study. Crit Care Nurs Clin North Am. 2018;30(2):259-71.

4. Mahmoudi H, Mohmmadi E, Ebadi A. Barriers to nursing care in emergency wards. Iranian journal of nursing and midwifery research. 2013;18(2):145. [Persian]

5. Oh N, Hong N, Ryu DH, Bae SG, Kam S, Kim KY. Exploring nursing intention, stress, and professionalism in response to infectious disease emergencies: the experience of local public hospital nurses during the 2015 MERS outbreak in South Korea. Asian Nurs Res. 2017;11(3):2306.

6. Siyu C, Xia M, Wen W, Cui L, Yang W, Liu S, Fan JF, Yue H, Tang S, Tang B, Li X. Mental health status and coping strategy of medical workers in China during The COVID-19 outbreak. MedRxiv. 2020 Jan 1.

7. Tam CW, Pang EP, Lam LC, Chiu HF. Severe acute respiratory syndrome (SARS) in Hong Kong in 2003: stress and psychological impact among frontline healthcare workers. Psychological medicine. 2004;34(7):1197-204.

8. Lee SM, Kang WS, Cho AR, Kim T, Park JK. Psychological impact of the 2015 MERS outbreak on hospital workers and quarantined hemodialysis patients. Comprehensive psychiatry. 2018;87:123-7.

9. Kim JS, Choi JS. Factors influencing emergency nurses' burnout during an outbreak of Middle East Respiratory Syndrome Coronavirus in Korea. Asian nursing research. 2016;10(4):295-9.

10. Kollie ES, Winslow BJ, Pothier P, Gaede D. Deciding to work during the Ebola outbreak: the voices and experiences of nurses and midwives in Liberia. Int J Africa Nurs Sci. 2017;7:75-81.

11. Phua DH, Tang HK, Tham KY. Coping responses of emergency physicians and nurses to the 2003 severe acute respiratory syndrome outbreak. Acad Emerg Medic. 2005;12(4):322-8.

12. Gorbalenya AE, Baker SC, Baric R, Groot RJ, Drosten C, Gulyaeva AA, Haagmans BL, Lauber C, Leontovich AM, Neuman BW, Penzar D. Severe acute respiratory syndrome-related coronavirus: The species and its viruses-a statement of the Coronavirus Study Group. BioRxiv. 2020.

13. Hick JL, Hanfling D, Wynia MK, Pavia AT. Duty to plan: health care, crisis standards of care, and novel coronavirus SARS-CoV-2. Nam Perspectives. 2020 Mar 5.

14. Correos JB. Lived Experience of Emerging Re-emerging Infectious Disease (ERID) Unit Nurses: The Untold Battle. Asia Pacific Journal of Multidisciplinary Research. 2018;6(3).

15. Eghbali M, Negarandeh R, Froutan R. COVID-19 epidemic: Hospital-level response. Nursing Practice Today. 2020;7(2):81-3. [Persian]

16. Shah K, Kamrai D, Mekala H, Mann B, Desai K, Patel RS. Focus on mental health during the coronavirus (COVID-19) pandemic: applying learnings from the past outbreaks. Cureus. 2020;12(3).

17. Buerhaus PI, Auerbach DI, Staiger DO. Older clinicians and the surge in novel coronavirus disease 2019 (COVID-19). Jama. 2020;323(18):1777-8.

18. Foyle A. I had depression caused by compassion fatigue. Cancer Nursing Practice. 2019;19(1):15.

19. Zhu Z, Xu S, Wang H, Liu Z, Wu J, Li G, Miao J, Zhang C, Yang Y, Sun W, Zhu S. COVID-19 in Wuhan: immediate psychological impact on 5062 health workers. MedRxiv. 2020. 
20. Ong JJ, Bharatendu C, Goh Y, Tang JZ, Sooi KW, Tan YL, Tan BY, Teoh HL, Ong ST, Allen DM, Sharma VK. Headaches associated with personal protective equipment-A cross-sectional study among frontline healthcare workers during COVID-19. Headache: The Journal of Head and Face Pain. 2020;60(5):864-77.

21. Karimi Z, Fereidouni Z, Behnammoghadam M, Alimohammadi N, Mousavizadeh A, Salehi T, Mirzaee MS, Mirzaee S. The lived experience of nurses caring for patients with COVID-19 in Iran: a phenomenological study. Risk management and healthcare policy. 2020;13:1271.

22. Rahmani R, Sargazi V, Jalali MS, Babamiri M. Relationship between COVID-19-caused Anxiety and Job Burnout among Hospital Staff: A Cross-sectional Study in the Southeast of Iran. Journal of Occupational Hygiene Engineering Volume. 2021;7(4):61-9. [Persian]

23. Khajeh Nouri Ranjbar M, Benisi P. The relationship between Covid-19 anxiety on depression and burnout and mental health of nurses. Seventh International Conference on Psychology, Counseling and Educational Sciences, 2020. https://civilica.com/doc/1136553/. [Persian]

24. Hassannia L, Taghizadeh F, Moosazadeh M, Zarghami M, Taghizadeh H, Dooki AF, Fathi M, Alizadeh-Navaei R, Hedayatizadeh-Omran A, Dehghan N. Anxiety and Depression in Health Workers and General Population During COVID-19 in IRAN: A Cross-Sectional Study. Neuropsychopharmacology Reports. 2021;41(1):40-9.

25. Shahyad SH, Mohammadi MT. Psychological impacts of Covid-19 outbreak on mental health status of society individuals: a narrative review. Journal of Military Medicine. 2020;22(2):184-92. [Persian]

26. Mirkazehi Rigi Z, Dadpisheh S, Sheikhi F, Balouch V, Kalkali S. Challenges and Strategies to deal with COVID-19 from the perspective of physicians and nurses in southern of Sistan and Baluchestan, Iran. Journal Mil Med. 2020;22(6):599-606. [Persian]

27. Keyvanara M, Shaarbafchizadeh N, Jangi M, Samouei R. Evaluating self-care barriers in prevention of COVID-19 according to healthcare experts and laypersons: A mixed study. Journal of Mazandaran University of Medical Sciences. 2020;30(189):117-25. [Persian]

28. Alizadeh A, Khankeh HR, Barati M, Ahmadi Y, Hadian A, Azizi M. Psychological distress among Iranian health-care providers exposed to coronavirus disease 2019 (COVID-19): a qualitative study. BMC psychiatry. 2020;20(1): 494.

29. Kalateh Sadati A, Zarei L, Shahabi S, Heydari ST, Taheri V, Jiriaei R, et al. Nursing experiences of COVID-19 outbreak in Iran: A qualitative study. Nursing Open. 2021;8(1):72-9.

30. Jackson D, Bradbury-Jones C, Baptiste D, Gelling L, Morin K, Neville S, Smith GD. Life in the pandemic: Some reflections on nursing in the context of COVID-19. J Clin Nurs. 2020;12(10).

31. Hirschmann MT, Hart A, Henckel J, Sadoghi P, Seil R, Mouton C. COVID-19 coronavirus: recommended personal protective equipment for the orthopaedic and trauma surgeon. Knee Surgery, Sports Traumatology, Arthroscopy. 2020;28(6):1690-8.

32. Moatti JP. The French response to COVID-19: intrinsic difficulties at the interface of science, public health, and policy. The Lancet. Public Health. 2020;5(5):e255.

33. Dossey L. Healers in the pandemic: honoring the ultimate sacrifice. Explore (New York, Ny). 2021 25.

34. Farrell K, Durand H, McSharry J, Meade O, Panel TH, Kenny E, Noone C, O'Connor LL, Lavoie KL, Byrne M, Mooney R. Exploring barriers and facilitators of physical distancing in the context of the COVID-19 pandemic: a qualitative interview study. HRB Open Research. 2021;4(50):50

35. Wittenberg E, Goldsmith JV, Chen C, Prince-Paul M, Johnson RR. Opportunities to improve COVID-19 provider communication resources: A systematic review. Patient Education and Counseling. 2021 Jan 9.

36. Weaver MS, Rosenberg AR, Fry A, Shostrom V, Wiener L. Impact of the Coronavirus Pandemic on Pediatric Palliative Care Team Structures, Services, and Care Delivery. J Palliat Medic. 2021;24(8):1213-20.

37. Weaver MS, Rosenberg AR, Fry A, Shostrom V, Wiener L. Impact of the Coronavirus Pandemic on Pediatric Palliative Care Team Structures, Services, and Care Delivery. J Palliat Medic. 2021;24(8):1213-20. 
38. Pahuja M, Wojcikewych D. Systems barriers to assessment and treatment of COVID-19 positive patients at the end of life. J Palliat Medic. 2021;24(2):302-4.

39. Williams RD, Brundage JA, Williams EB. Moral injury in times of COVID-19. J Health Service Psychol. 2020;46(2):65-9.

40. Wang Z, Harold KG, Tong Y, Wen J, Sui M, Liu H, Zaben FA, Liu G. Moral injury in Chinese health professionals during the COVID-19 pandemic. Psychological Trauma: Theory, Research, Practice, and Policy. 2021 May 27.

41. Silverman HJ, Kheirbek RE, Moscou-Jackson G, Day J. Moral distress in nurses caring for patients with Covid-19. Nursing Ethics. 2021 29:09697330211003217. 